\title{
Energy Efficiency Options for the New England Demand Response Initiative (NEDRI) - Framing Paper \#4
}

\author{
Prepared for \\ Prepared by \\ Jeff Schlegel \\ Schlegel \& Associates, LLC \\ 1167 W. Samalayuca Drive \\ Tucson, Arizona 85704-3224
}

The New England Demand Response Initiative (NEDRI)

May 2002

Download from: http://eetd.lbl.gov/EA/EMP/

The work described in this study was funded by the Assistance Secretary of Energy Efficiency and Renewable Energy, Office of Power Technologies of the U. S. Department of Energy under Contract No. DE-AC03-76SF00098 


\section{Table of Contents}

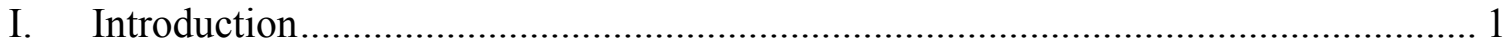

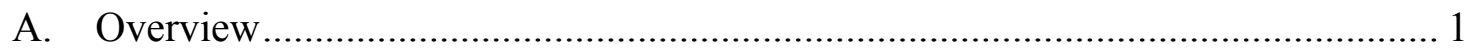

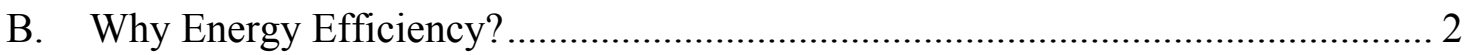

C. Energy Efficiency Compared to Load Management ……………........................... 3

D. Policy, Program, and Market Issues ……………................................................. 6

II. Energy Efficiency Experience and Potential in New England and Other Regions .... 8

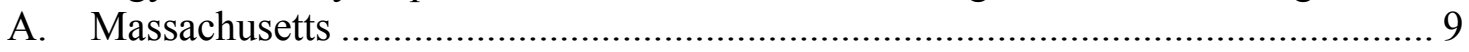

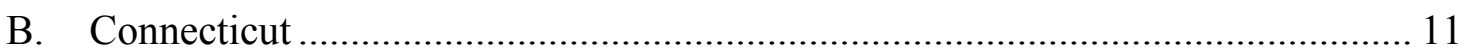

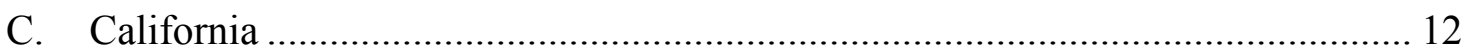

D. Building Codes and Appliance and Equipment Standards …………………….... 14

E. Effects of Energy Efficiency on Market Prices ................................................. 16

F. Energy Efficiency as a Distributed Resource ………......................................... 18

G. Targeted Energy Efficiency Efforts .................................................................... 18

H. Remaining Potential and Goals for Energy Efficiency........................................ 19

III. Energy Efficiency in a Market Framework ………......................................... 21

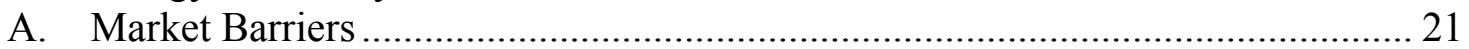

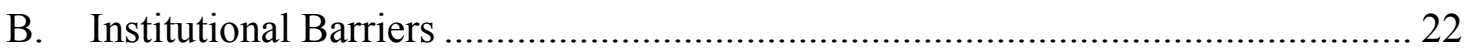

C. Market Orientation of Energy Efficiency Programs ............................................ 22

IV. Energy Efficiency Options.......................................................................... 24

A. Primary Funding and Program Focus Options.................................................... 24

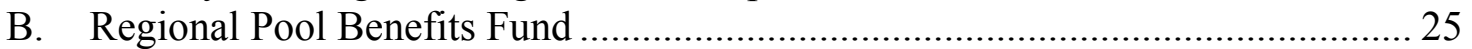

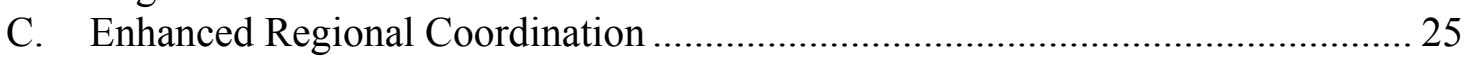

D. Other Complementary Approaches....................................................................... 27

E. Technology Options for Joint Delivery of Efficiency and Load Management .... 27

F. Options and Characteristics of Options for Energy Efficiency ............................. 27

G. Energy Efficiency Program Designs for Peak Load Demand Response .............. 30

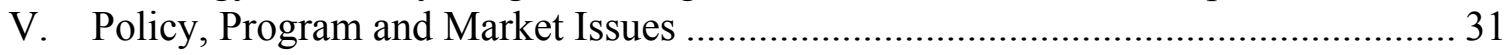

VI. Bibliography .......................................................................................... 40 


\section{Introduction}

\section{A. Overview}

By definition, effective and efficient competitive markets need a supply side and a demand side. One criticism of electric restructuring efforts in many states is that most of the attention has been focused on the supply side, in a market focused on the short term. In general, the demand side of the market has been under-addressed.

The objective of the New England Demand Response Initiative (NEDRI) is to develop a comprehensive, coordinated set of demand response programs for the New England regional power markets. NEDRI aims to maximize the capability of demand response to compete in the wholesale market and to improve the economic efficiency and environmental profile of the electric sector. To those ends, NEDRI is focusing its efforts in four interrelated areas:

- ISO-level reliability programs,

- Market-based price-responsive load programs,

- Demand response at retail through pricing, rate design, and advanced metering, and

- $\quad$ End-use energy efficiency resources as demand response.

The fourth area, energy efficiency, is the subject of this framing paper.

Energy efficiency ${ }^{1}$ reduces the energy used by specific end-use devices and systems, typically without affecting the level of service and without loss of amenity. Energy savings and peak load reductions are achieved by substituting technically more advanced equipment, processes, or operational strategies to produce the same or an improved level of end-use service with less electricity. In contrast, load management programs lower peak demand during specific, limited time periods by either (1) influencing the timing of energy use by shifting load to another time period, or (2) reducing the level of energy use by curtailing or interrupting the load, typically with some loss of service or amenity ${ }^{2}$ (see Section I.C for further discussion).

Following this introduction, Section II documents energy efficiency experience and potential in New England and other regions. Section III discusses energy efficiency in a market framework, and summarizes market and institutional barriers to increasing energy efficiency in society. Section IV summarizes key energy efficiency options in terms of funding sources and primary focus. Finally, policy, program, and market issues for NEDRI stakeholder consideration and discussion are found in Section V.

The central conclusion of this framing paper is: cost-effective energy efficiency programs make electricity markets more competitive and more efficient, significantly improve the

\footnotetext{
${ }^{1}$ Throughout this paper, "energy efficiency" is shorthand, meaning "cost-effective energy efficiency from the perspective of the total resource or societal test."

${ }^{2}$ Generally the loss of service or amenity is deemed acceptable by building managers for short time periods, and many of today's more effective demand response load management programs focus on areas of excessive energy use in buildings, such as areas that are over-lit or over-cooled.
} 
reliability of the electric system in New England, and reduce the costs and environmental impacts of electric service. Therefore, the states and region should consider regulatory, institutional, and market reforms that would increase the region's reliance on energy efficiency as a resource, together with other beneficial demand-side resources.

Many policy makers in New England appear to agree. For example, in July 2001, the Coalition of Northeastern Governors issued an Energy Policy Statement that included the declaration: "Conservation, energy efficiency, and demand management are viable and cost-effective strategies for meeting energy needs, and are necessary components of a balanced national energy strategy."

The discussion and analysis in this paper are built upon the foundation laid in Richard Cowart's report prepared for NARUC, Efficient Reliability: The Critical Role of Demand-Side Resources in Power Systems and Markets. ${ }^{3}$ This NEDRI framing paper builds upon Cowart's report in two main ways, by broadening the discussion to include all system needs (not limited just to reliability), and by narrowing the focus to explore energy efficiency as one of several valuable demand-side resources.

\section{B. Why Energy Efficiency?}

Energy efficiency is effective on the demand side of the market by reducing load, peak demand, and energy consumption. Cost-effective energy efficiency load reductions result in lower costs of electric service for consumers who install energy efficiency measures, and lower total costs for all consumers on the grid. Load reductions from energy efficiency reduce market prices for everyone purchasing power in the market (wholesale and retail). Energy efficiency also reduces the environmental impacts of electricity generation and transmission.

Energy efficiency is often less costly and more cost effective compared to central generation, transmission, and distribution. Also, compared to supply options, energy efficiency is more distributed with no need for transmission or distribution, more diverse, less risky in terms of market and fuel price volatility, less subject to security risks and interruptions, and much less harmful to the environment. Energy efficiency programs provide financial and other benefits to consumers and businesses, and they create jobs and improve the economy.

Energy efficiency programs provide meaningful choices and opportunities for customers of all sizes, including industrial, commercial, small business, and residential customers. In fact, energy efficiency provides what may be the most effective option for reducing the cost of energy service for many small, medium, and even large customers - by focusing on efficient energy use and reducing load, thereby reducing the size of the bill, not just focusing on the rate or price of generation service.

\footnotetext{
${ }^{3}$ Richard Cowart, Efficient Reliability: The Critical Role of Demand-Side Resources in Power Systems and Markets, National Association of Regulatory Utility Commissioners, June 2001.
} 


\section{Energy Efficiency Compared to Load Management}

How does energy efficiency, as one type of demand-side resource, compare to load management, as one example of a shorter-term demand response program? What public and pool/system benefits are provided by energy efficiency versus load management?

To explore this issue, we developed an illustrative example for an existing large commercial office building located in Albany, NY - the closest location to New England for which we had 8760 hour load shape data - and examined the impacts on peak load and load shape on a summer day (July 9). ${ }^{4}$ We analyzed two primary scenarios: (1) energy efficiency measures for lighting and cooling that reduced load by $20 \%{ }^{5}$; and (2) load management defined as a four-hour curtailment from 1:00 pm to 5:00 pm, with a curtailment load reduction of $15 \%$ achieved by reducing lighting and HVAC load. ${ }^{6}$

The comparison in this section is illustrative, using one example of a large commercial office building, and it does not necessarily represent all energy efficiency or all load management. The point of the illustration is that energy efficiency is different than load management - and both are valuable demand-side resources in their own ways.

\section{Energy efficiency can reduce load significantly, and the load reductions occur over many hours of the load shape and for many days of the year, thereby saving energy as well as reducing peak demand.}

The different impacts of energy efficiency and load management are illustrated in the following graphs:

- Comparison of the existing building baseline with load management (four-hour curtailment) to the energy efficiency case.

- Comparison of the existing building baseline to the combination of energy efficiency and load management.

The first graph shows significant load reductions from the energy efficiency investments, and that these load reductions occur over many hours of the load shape, resulting in significant energy savings as well as reductions in peak demand. Load management also results in significant load reductions (and the load reductions could be larger or smaller in other situations), but the load reductions occur over far fewer hours.

\footnotetext{
${ }^{4}$ Thanks to John Plunkett and Eric Belliveau of Optimal Energy for their assistance in developing this load shape example.

${ }^{5}$ We used a conservative estimate of $20 \%$ load reduction from the HVAC and lighting energy efficiency measures to avoid overstating the case. For existing, previously-untreated large commercial office buildings in New England, savings of 25\% or more from comprehensive measures are common, and savings of $20 \%$ are near universal.

${ }^{6}$ Load reduction of $15 \%$ from four-hour load curtailment based on facilities that used lighting and HVAC strategies to reduce load. See Goldman et al, Do "Enabling Technologies" Affect Customer Performance in Price-Responsive Load Programs?
} 


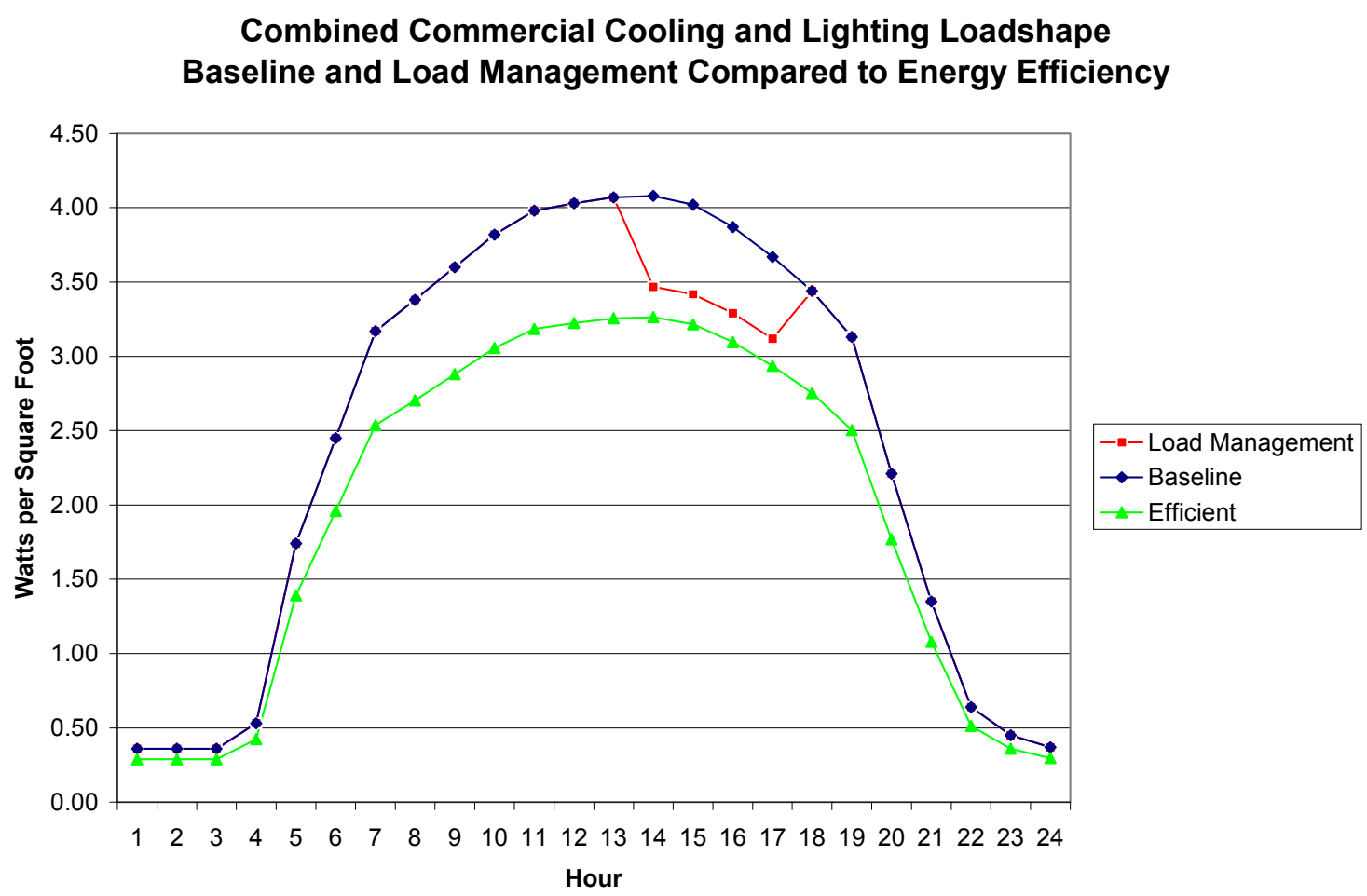

Combined Commercial Cooling and Lighting Loadshape with Efficiency and Load Management (Four-Hour Curtailment by 15\%)

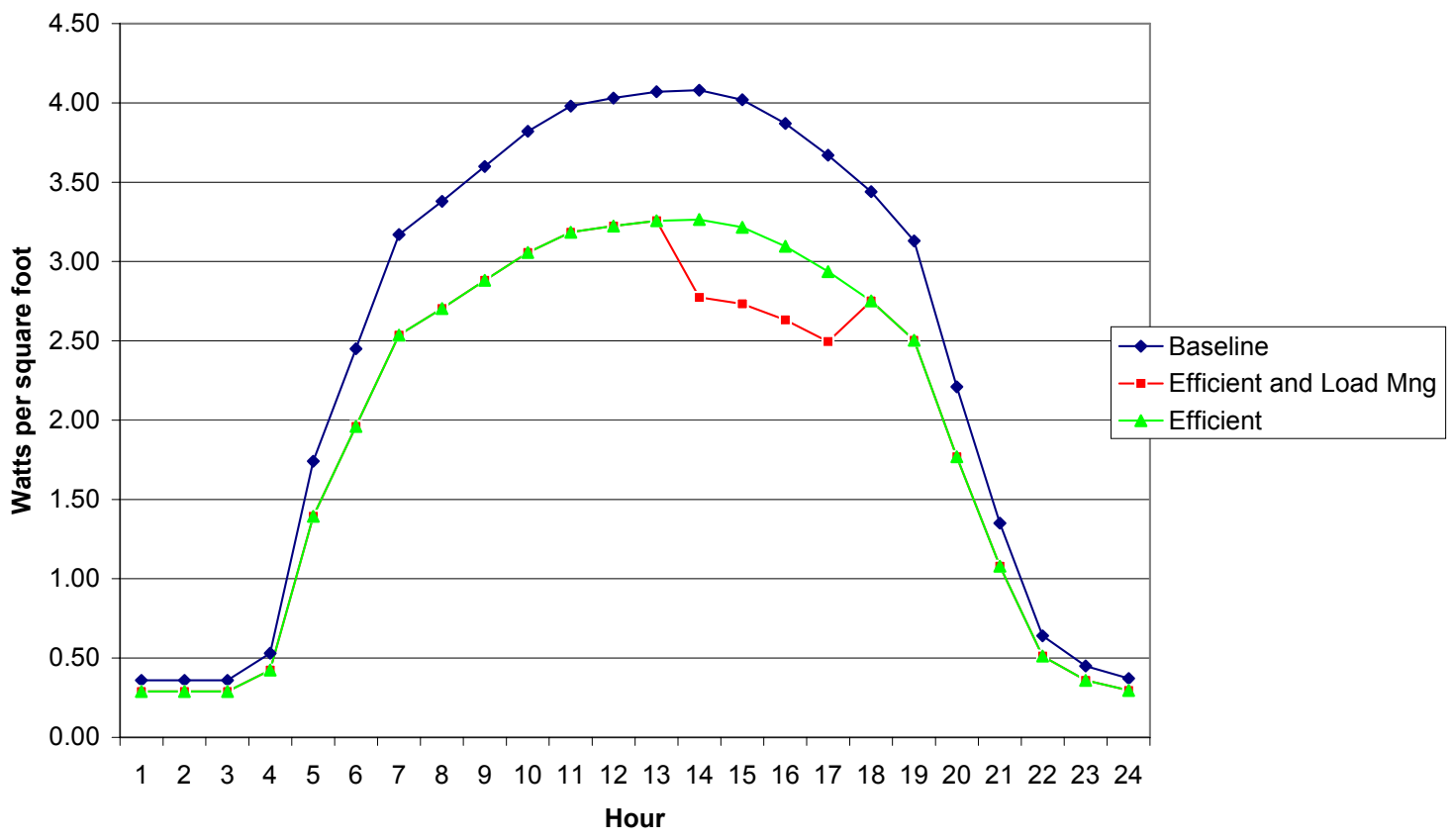


The second graph shows that energy efficiency and load management could be implemented together, and that doing so results in even larger total peak load reductions, as well as cost-effective energy savings (and the associated environmental benefits). Energy efficiency and load management are different, but both are valuable approaches to load reduction - and they can be even more valuable when done together.

Note that other examples of load management will look different, especially load management in industrial facilities with emergency backup generation, where load curtailment can result in load reductions of $50-70 \%$. However, the central point remains: energy efficiency can reduce load significantly over many hours of the load shape, for many days of the year, and provide energy savings as well as peak demand reductions.

\section{Energy efficiency reduces load over the life of the energy efficient measure, typically for many years.}

Energy efficiency measures have effective measure lives of up to 20 years, with an average of about 10-15 years for commercial and industrial facilities. Once they are installed, the energy efficiency measures deliver reduced load for many years. There is no need to re-sign or re-commit the load reduction in subsequent years.

\section{Energy efficiency does not reduce the level of end-use service or amenity.}

In contrast, load management typically results in some loss of service and amenity, e.g., through reduced use of the managed facility, reduced production or productivity, and/or reduced comfort. ${ }^{7}$ Today's most effective load management programs attempt to minimize the perceived loss of service or amenity, and generally the loss of service or amenity is deemed acceptable by building managers for short time periods.

\section{Energy efficiency resources are automatically dispatched and always on.}

Energy efficiency resources are automatically dispatched by customers coincident with the use of the underlying end-use equipment. Therefore, they are always on without delay, and do not require market or system intervention by system operators or schedulers.

\section{Energy efficiency captures lost opportunities and reduces the addition of inefficient load.}

Each time a customer selects an inefficient product or service compared to an energy efficient one, there is a lost opportunity, and inefficient load is added to the grid. The inefficient load will remain on the grid until it is retrofitted or replaced. And, in general, it will cost more to retrofit inefficient installed load than it would have cost to install energy efficient products or services in the first place.

\footnotetext{
${ }^{7}$ Though the level of service and amenity lost could be restored through alternate supply sources, such as emergency backup generation, for those customers with such backup generation.
} 
From the perspective of efficient systems operation, one could miss capturing a single year of load reduction from a potential load management customer, go without that one year of load reduction, and hope to sign up the customer and install the enabling infrastructure the following year. But one does not want to miss an opportunity to install efficient over inefficient load, e.g., as part of a market-driven opportunity such as equipment replacement, new construction, or building remodeling, because once installed, the inefficient load will remain on the system for years.

\section{Energy efficiency reduces the environmental impacts of electricity generation, transmission, and distribution.}

In addition to reducing peak load, energy efficiency saves energy over many hours of the load shape for years, thereby reducing environmental emissions from generators and the environmental impacts of increased electricity transmission and distribution.

\section{Energy Efficiency Support Options}

There are several options for public and system support of energy efficiency summarized in this paper, including:

- State system benefits funds collected through wires charges to support broad-based energy efficiency programs and activities;

- Regional pool benefits programs funded through transmission tariffs or uplift charges, for programs with cost-effective regional reliability or pool benefits;

- Building codes and appliance and equipment standards to reduce inefficient load and to lock in efficiency gains in the marketplace;

- Targeted least-cost distribution investments by distribution companies to defer or reduce future wires investments, or to relieve distribution constraints, financed with utility funds and recovered through future revenues, or recovered through pool reimbursement for load reductions;

- Targeted least-cost transmission investments by transmission companies or the regional pool to defer or reduce future wires investments, or to relieve transmission constrained areas, financed with transmission company funds and recovered through future revenues, or financed through the regional pool, with wires investments subject to bidding and open season mechanisms;

- Enhanced regional coordination to improve the effectiveness and efficiency of energy efficiency efforts in New England, possibly through a regional energy efficiency coordinating council;

- Other complementary approaches such as financing support, shared savings programs, and Pay As You Save (PAYS) programs; and

- Fiscal policies such as tax incentives.

These options are discussed further in Section IV.

\section{E. Policy, Program, and Market Issues}


Section $\mathrm{V}$ of this paper presents a number of challenging policy, program, and market issues for NEDRI stakeholder consideration and discussion.

The vast majority of energy efficiency options and issues discussed are appropriate both for the current market (considering that New England does not currently have a fully functioning and active demand response market) and for the market design of the future. The New England states have an advantage over most other states in the depth and breadth of utility and public efficiency programs offered over the years. Each of the six states has also reconfirmed public policy support for efficiency in restructuring or in other recent initiatives. Energy efficiency provides value in the current market and regulatory system, and can continue to provide value in future markets, by reducing load and capturing lost opportunities. The policy discussion in Section V presents some of the major challenges to continuing progress on energy efficiency in a de-integrated utility system, along with some of the leading options to meet those challenges. 


\section{Energy Efficiency Experience and Potential in New England and Other Regions}

New England has been investing in energy efficiency as a cost-effective and valuable resource for more than a decade. States and utilities have achieved net benefits (i.e., benefits exceeding costs) of several billion dollars. One estimate, from a 1999 report by three utilities serving portions of New England, concluded that the three utilities spent approximately $\$ 1$ billion promoting energy efficiency within the business community to leverage almost $\$ 3$ billion in energy savings through avoided electricity purchases over the lifetimes of the installed measures. ${ }^{8}$ New capacity needs were reduced by almost 1,000 MW. The resulting \$2 billion in net benefits were achieved in the business (C\&I) sector alone - savings and net benefits in the residential and low income sectors, and savings since 1999, would be on top of that amount.

In Massachusetts alone, cumulative summer peak load savings from energy efficiency (not including load management) were about $650 \mathrm{MW}$ as of 2000. These peak demand savings are stated as currently-available, meaning that they account for retirement of energy efficiency measures whose useful lives have ended.

Even though New England has been investing in energy efficiency for many years, there appears to be a large amount of cost-effective energy efficiency potential remaining. For example, one 2001 study in Massachusetts concluded that while Massachusetts had made significant gains in energy efficiency as the result of past programs, there remained significant potential for continued cost-effective investments in energy efficiency, in both the residential and C\&I sectors. ${ }^{9}$

There are other indications that there is plenty of energy efficiency potential remaining. For example, in recent years, many energy efficiency program budgets, especially for some major C\&I programs in Massachusetts and Connecticut, have been almost fully committed by mid year, indicating a large reservoir of customer demand for energy efficiency opportunities. In energy efficiency program planning processes across the states, some cost-effective energy efficiency opportunities are being foregone solely because of budget limitations. And the higher value of load reductions displayed in power markets in recent years would increase the avoided costs and therefore the costeffectiveness of energy efficiency, thereby adding more cost-effective measures and programs to the list of options. Also, consumers and business are building new and remodeling existing buildings, purchasing new or replacing existing appliances and equipment, and modifying business operations or industrial processes all the time - and each of these market events provides another opportunity to improve energy efficiency above the baseline in the current marketplace.

\footnotetext{
${ }^{8}$ See $A$ Decade of Progress with Business Energy Efficiency in New England, prepared by Boston Edison, the NEES Companies, and Northeast Utilities, July 1999.

${ }^{9}$ See RLW \& SFMC, 2001.
} 
This section describes energy efficiency experience and potential in New England and other regions. Summary data are presented for selected states in New England and selected other regions where such summary data were readily available in public reports. In addition, the experience and potential for building codes and equipment standards, the impact of energy efficiency load reductions on market prices, and experience with targeted T\&D energy efficiency efforts, are summarized.

\section{A. Massachusetts}

Energy efficiency programs have provided substantial, cost-effective, and reliable resources in Massachusetts for many years. Currently, Massachusetts has a broad-based system benefits fund program funded at $\$ 0.0025 / \mathrm{kWh}$ of electric energy sales.

In Massachusetts, in-state annual peak load reductions from both energy efficiency and SBC-funded load management programs have ranged from 98 to $135 \mathrm{MW}$ for 1998 , 1999, and 2000. Total cumulative peak load reductions in Massachusetts from energy efficiency and load management were approximately $700 \mathrm{MW}$ as of 2000.

For energy efficiency alone, annual peak load reductions have been about 50 to $60 \mathrm{MW}$ for each of 1998, 1999, and 2000. Total cumulative peak load reductions in Massachusetts from energy efficiency alone are approximately $650 \mathrm{MW}$. These peak demand savings are stated as currently-available, meaning that they account for retirement of energy efficiency measures whose useful lives have ended.

The annual contribution to cumulative peak demand savings from energy efficiency has been roughly equivalent to the contribution from SBC-funded load management, but the cumulative contribution to load reduction is largely from energy efficiency.

The figure below shows that without the $51 \mathrm{MW}$ of energy efficiency summer peak load reductions in 2000 , the summer peak would have been .6\% higher. The summer peak would have been $7.2 \%$ higher without the $648 \mathrm{MW}$ of cumulative energy efficiency summer peak load reductions. The comparison is to the 1999 system peak, which was higher than the 2000 summer peak.

These peak demand savings are from broad-based energy efficiency programs. The programs were not targeted specifically or primarily to provide summer $\mathrm{kW}$ savings. Increasing focus on a summer peak savings objective would likely increase the annual summer peak load reductions going forward. This consideration should be made in a process that considers all of the goals and objectives of SBC-funded energy efficiency programs. 


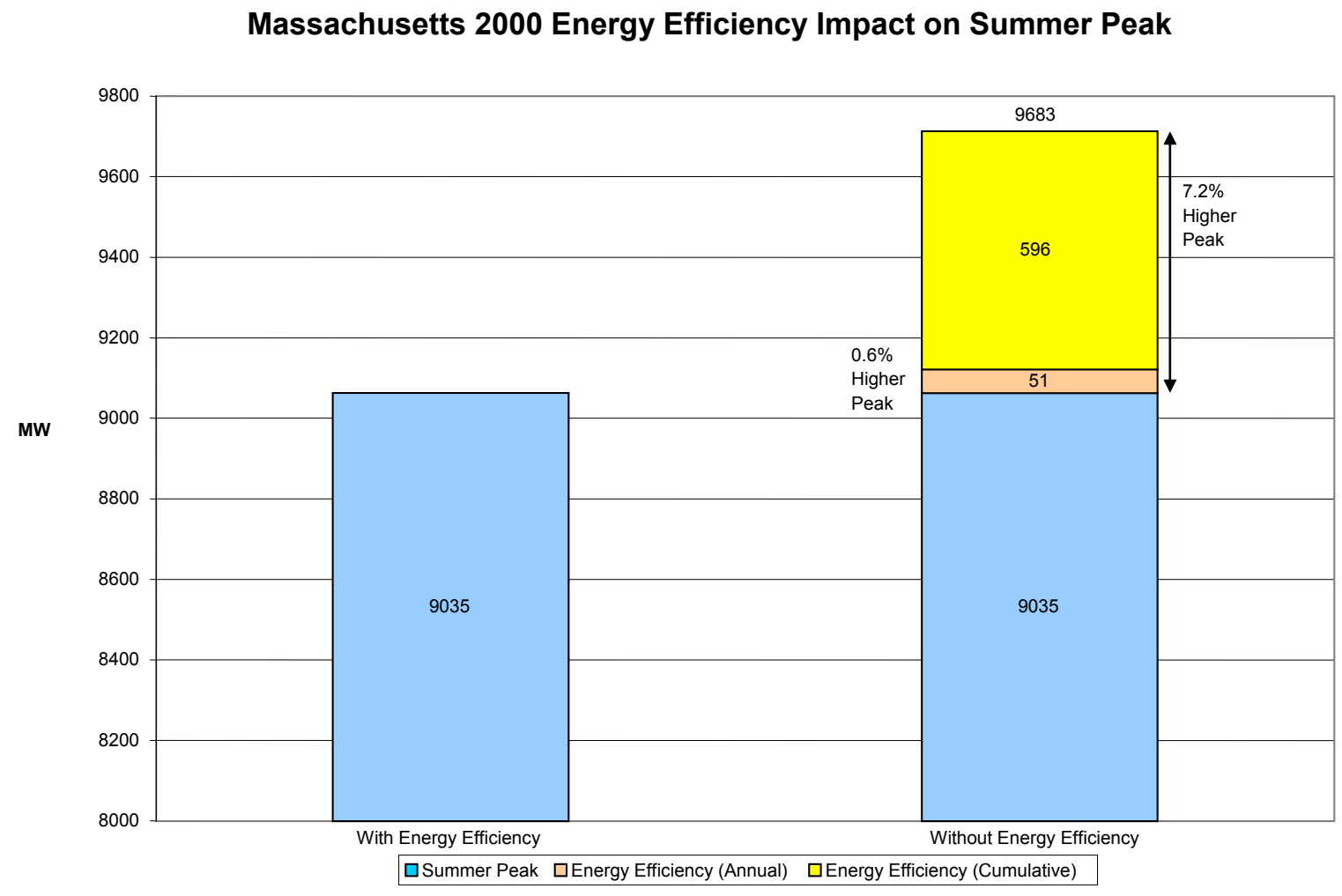

At one Massachusetts distribution company (MECo), the energy efficiency peak demand savings have been equivalent to $20 \%$ to $30 \%$ of load growth over the last few years.

In terms of energy savings, cost-effectiveness, and the cost of conserved energy, the Massachusetts DOER concluded:

"During the 1990s, energy efficiency programs secured significant economic and environmental benefits that the market, acting alone, would not have captured. For example, over the five-year period 1995-1999, ratepayer-funded energy efficiency programs resulted in electricity savings totaling 18,000 million $\mathrm{kWh}$ over the period that the efficiency measures remain in place. These savings were achieved at a total cost of $\$ 665$ million (in $\$ 1999$ ). ${ }^{10}$ This translates to a cost for conserved electricity of $3.7 \mathrm{k} / \mathrm{kWh}$ over the five-year period.

During this same five-year period, the total benefit realized by all customers from these programs was $\$ 854$ million. Comparing costs of $\$ 665$ million against benefits of $\$ 854$ million yields a cost-benefit ratio for these programs of 1.3. The

\footnotetext{
${ }^{10}$ This total cost includes program expenditures (funded through the ratepayer energy efficiency charge) as well as participant costs. Participant costs are defined as the investment a customer makes in an energy efficiency project over and above what is funded by ratepayer funded energy efficiency programs. Specifically, participants pay directly for a portion of the incremental cost of higher efficiency equipment (relative to standard equipment), while the balance of the incremental cost is funded through the energy efficiency programs.
} 
calculation of benefits associated with these programs includes the costs that were avoided by the electric utilities as a result of the reduced demand for electricity that resulted from the energy efficiency measures taken. Without these energy efficiency programs, costs associated with that additional electrical demand would have been passed on to all utility customers through higher electricity rates."

\section{Historical Comparison of Massachusetts Costs and Benefits} 1995-1999

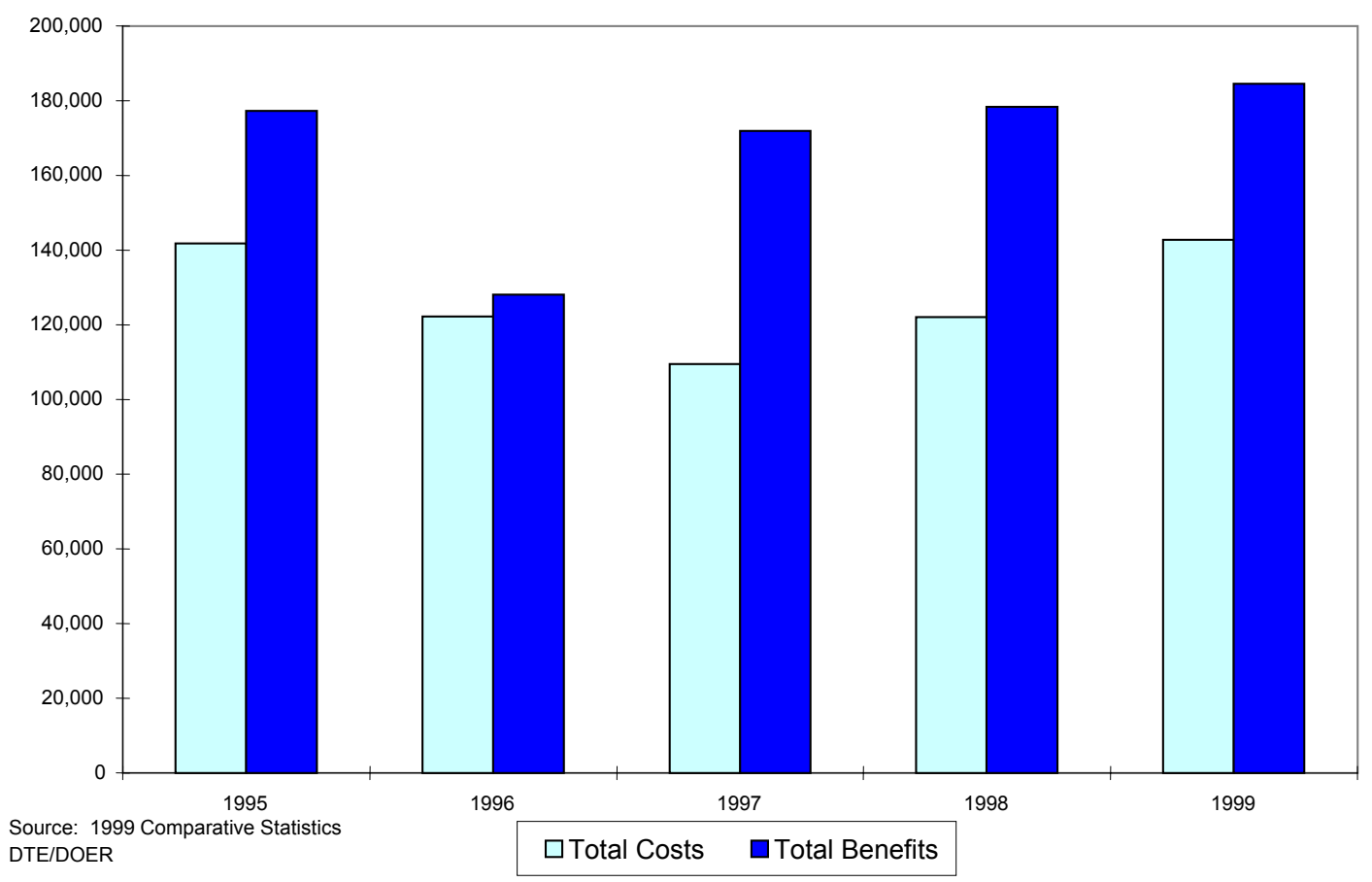

Note that in the DOER benefit/cost analysis summarized above, some benefits were not included, such as the full value of environmental benefits, reliability benefits, reduced electricity market prices, and reduced natural gas consumption and the corresponding effect on natural gas prices.

The energy efficiency programs have also provided environmental benefits. In Massachusetts, the 1999 energy efficiency programs improved air quality in the state and region, reducing emissions of NOx, $\mathrm{SO}_{2}$, and $\mathrm{CO}_{2}$ by 453 tons, 770 tons, and 145,000 tons in 1999 alone, respectively. Over the lifetime of the measures installed in 1999, the emission reduction impacts of these pollutants should be substantially greater.

\section{B. Connecticut}

According to the Connecticut Energy Conservation Management Board (ECMB) year 2001 annual report to legislature, the 2001 conservation and load management (C\&LM) programs provided peak demand savings of $65.6 \mathrm{MW}$, and projected 2002 savings of 
67.2 MW. The energy efficiency programs alone provided 55 MW of the peak demand savings in 2001.

The 2001 C\&LM programs also provided energy savings of 4,735 million kWh over the lifetimes of the measures. The energy efficiency programs reduced pollution and provided other environmental benefits by lowering demand and power production, thereby limiting emissions.

\section{California}

For decades, California has made a significant commitment to energy efficiency and DSM as an essential component of its total resource mix, and the state has achieved large peak load reductions as a result. In 1999, the California Energy Commission (CEC) stated, "Since 1975, a combination of State energy efficiency standards for buildings and appliances and utility energy efficiency programs have reduced electricity and natural gas consumption in California by over 470,000 gigawatt hours and over 50 billion therms. The displaced energy from both standards and programs was roughly the equivalent of fourteen 700 megawatts power plants," or about 9,800 MW (CEC, 1999).

The figure below from the CEC shows peak load reductions by year from 1975 through 2000 from California appliance standards, building codes, energy efficiency programs, and other sources. Appliance standards, building codes, and energy efficiency programs accounted for more than $9,000 \mathrm{MW}$ of the peak load reductions. 
California Peak Load Reductions (MW), 1975 - 2000 From Appliance Standards, Building Standards, and Energy Efficiency Programs

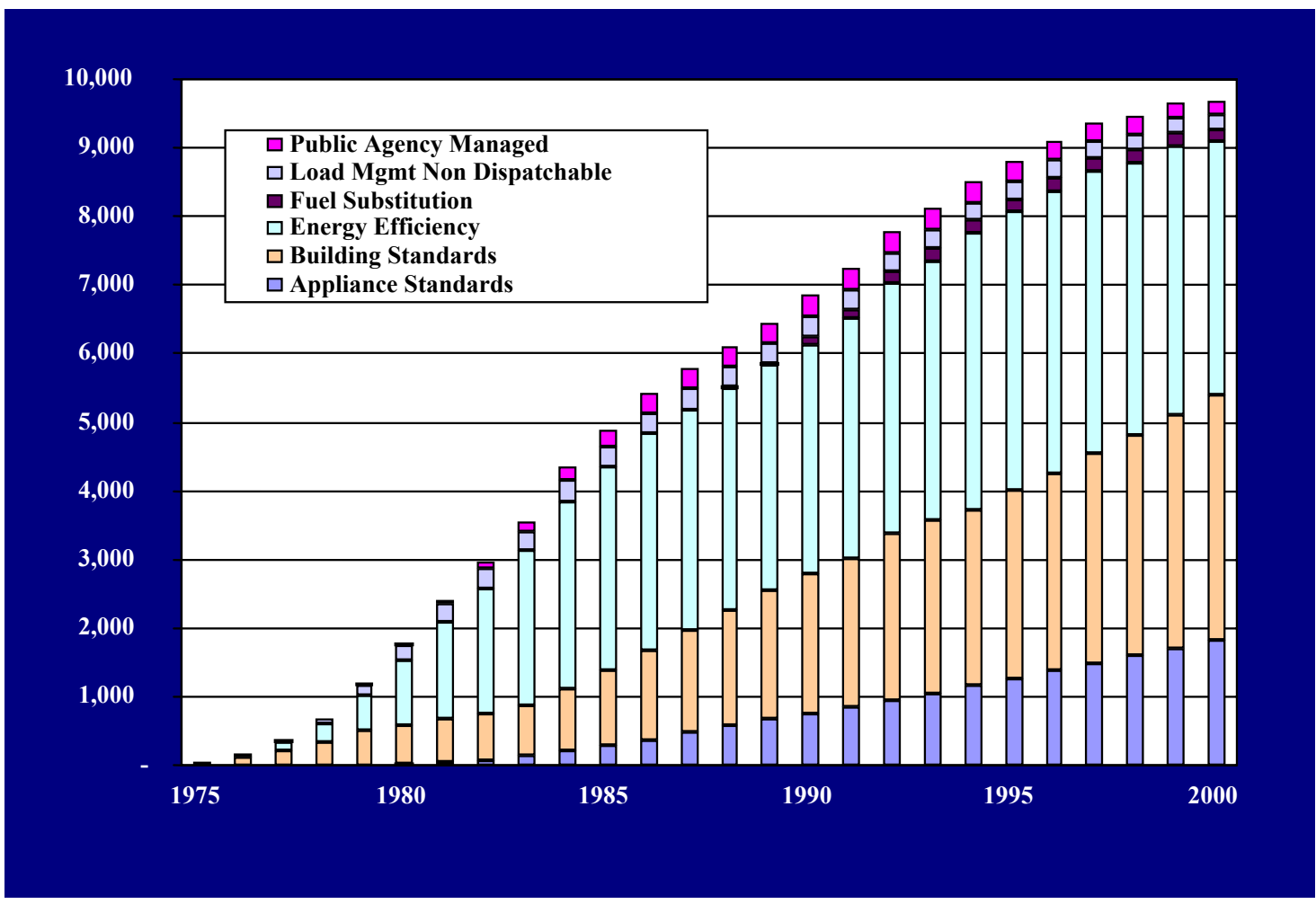

The historical California experience is also summarized in the Natural Resources Defense Council (NRDC) report entitled Energy Efficiency Leadership in a Crisis: How California is Winning. ${ }^{11}$ This report states that electricity use in CA grew only $1.1 \% / \mathrm{yr}$ on average during $1990-99$, compared to about $2.5 \%$ yr on average nationwide. It also concludes that DSM programs have had an average cost of saved energy of 2.5 cents/kWh, and that programs run during 1990-98 provided net benefits of $\$ 3$ billion.

More recently, reduced demand due to cost-effective energy efficiency programs, building and appliance standards, and voluntary reductions was a major reason why California avoided rolling blackouts in the summer of 2001. According to Goldman et al:

"During summer 2001, Californians reduced electricity usage by $6 \%$ and average monthly peak demand by $8 \%$, compared to summer 2000 . These load reductions played an important role in avoiding the hundreds of hours of rotating power outages predicted several months prior." (Goldman et al, 2002)

The report also concluded that consumer actions to reduce electricity consumption were the driving force behind the load reductions observed in summer 2001, and utility energy efficiency programs exceeded savings goals and played a major role in reducing customer loads in summer 2001.

\footnotetext{
${ }^{11}$ The report is available on the NRDC web site at www.nrdc.org.
} 


\section{Building Codes and Appliance and Equipment Standards}

Because they apply to all products sold or installed in a market, standards can have huge impacts on energy use. As of 2000, standards had already cut U.S. electricity use by 2.5 percent, reduced national peak electricity demand by 20,000 megawatts, saved U.S. energy users more than $\$ 50$ billion and cut U.S. carbon emissions from fossil fuel use by nearly 2 percent (Geller, Kubo and Nadel, 2001). Over the next 20 years, these savings will grow by a factor of roughly three as consumers and businesses replace worn out products with products that comply with current standards and recently approved standards take effect. ${ }^{12}$

Several states and regions have made a commitment to grow efficiently, not inefficiently, through the implementation of building codes and appliance and efficiency standards. Two examples of the current status and past and future benefits follow - for New England and California.

\section{New England}

In June 2001, the Northeast Energy Efficiency Partnerships (NEEP) launched the Northeast States Energy Efficiency Standards Project. The analysis performed for the project found that new or updated efficiency standards for 15 products could reduce the projected electric energy requirement for the 10-state Northeast region in 2020 by more than 25 percent, or nearly 47,000 gigawatt hours $(\mathrm{GWh})$, roughly equivalent to the electricity consumption of Massachusetts in 2000. The standards would save business and residential energy consumers nearly $\$ 27$ billion by 2020 .

By reducing energy demand across the entire Northeast region, energy efficiency standards could serve as one very low-cost and effective way of coping with projected growth in overall demand and related issues such as planned transmission investments and load pockets. The potential reduction in peak demand in the 10-state Northeast region (New England, NY, PA, NJ, MD) by 2020 from the new or updated efficiency standards is over $16,500 \mathrm{MW}$, equivalent to the output of $33500-\mathrm{MW}$ power plants (see figure below).

In the New England Power Pool (NEPOOL) alone, standards could reduce peak demand in 2020 by about $2,550 \mathrm{MW}$, equivalent to 27 percent of projected load growth. These new or updated standards could make a significant contribution to restraining projected demand growth in the region's power pool, potentially postponing or avoiding a substantial fraction of investment in new generation plants as well as transmission and distribution system upgrades.

\footnotetext{
${ }^{12}$ This a conservative estimate since it only includes only the savings from the national program, since 1987, and does not include the savings from the earlier state standards.
} 


\section{Projected Northeast Regional Electric Demand With and Without New/Updated Efficiency Standards}

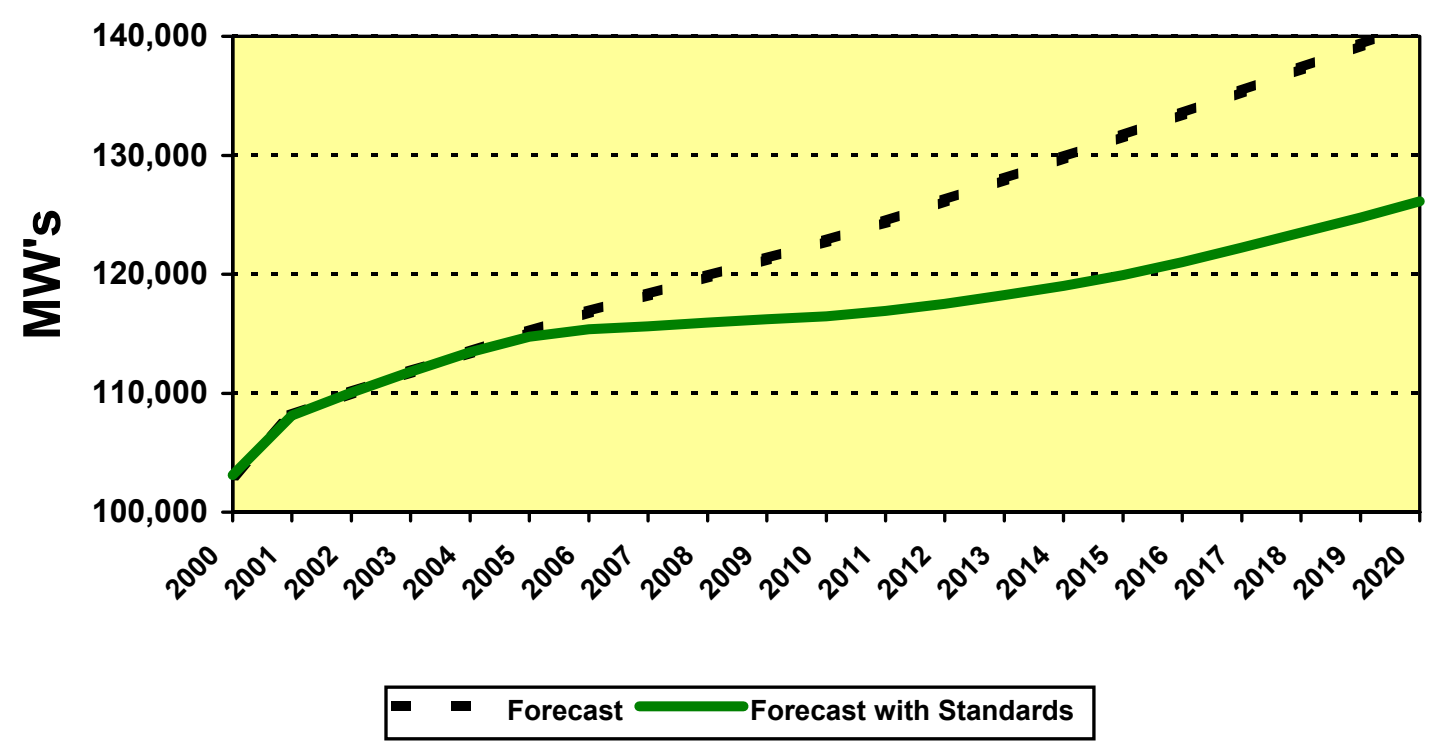

NEEP has also been conducting analysis on building codes. Recent NEEP analysis estimates that the combination of improved building codes and appliance and equipment standards will result in peak load reductions of 25,000 MW for the 10-state Northeast region, and 3,450 MW in the NEPOOL region, by 2020.

\section{California}

In California, the energy efficiency building codes and appliance standards have resulted in over 5,000 MW of peak load reductions (see graph in Section II.C above). The Title 24 Energy Efficiency Standards for Residential and Nonresidential Buildings were established in 1978 in response to a legislative mandate to reduce California's energy consumption. The building standards are updated periodically to allow consideration and possible incorporation of new energy efficiency technologies and methods. New building standards were adopted by the CEC in 2001 as mandated by Assembly Bill 970 to reduce California's electricity demand. The new building standards went into effect on June 1, 2001.

The CEC recently conducted an expedited rulemaking process to consider amendments to the current Appliance Energy Efficiency Standards to comply with Assembly Bill 970. The bill directed the CEC to update the standards at the earliest feasible date. A primary reason for this legislative action was to respond to trends in electricity peak demand that strained the adequacy and reliability of California's electricity system.

The expedited rulemaking recently reached its conclusion with the CEC's unanimous adoption on February 6,2002 of a new set of efficiency standards. The effective date for revised regulations regarding enforcement, reporting of data and labeling of appliances is 
July 1, 2002. They include new or upgraded standards for residential central air conditioners, commercial air conditioners, refrigerating beverage vending machines, commercial refrigerators and freezers, exit signs, traffic signals, torchiere lighting fixtures, commercial clothes washers and distribution transformers. Most of these new minimum efficiency standards become effective on March 1, 2003. California will need to apply for and receive a waiver from the federal standards for several key measures.

According to the CEC, the combination of energy efficient building standards and appliance standards have saved more than $\$ 20$ billion in electricity and natural gas costs in California. The CEC estimates that the standards will save $\$ 57$ billion by 2011 .

\section{E. Effects of Energy Efficiency on Market Prices}

Energy efficiency reduces peak demand, and therefore it can and has reduced market prices for everyone purchasing electricity in the power market. For example, the Massachusetts DOER 1999 annual report found:

"The situation that occurred in the New England power pool on June $7^{\text {th }}, 1999$ illustrates this phenomena of market-price reduction as a result of energy efficiency activities. June $7^{\text {th }}$ was an unusually hot day for that time of year, and the electricity system in New England was not fully prepared to meet the unexpected high demand for electricity during the peak hours of the day (9am to $10 \mathrm{pm}$ ), given the number of plants that were off-line for maintenance, etc. During this 13-hour period, New England's electricity demand reached an average peak of 21,394 MW, where during those hours market prices reached an average of $\$ 392$ per MW (where the highest hourly price was $\$ 680$ per MW). Had there not been $115 \mathrm{MW}$ in energy efficiency related demand reductions during each of these 13 hours $^{13}$, the average peak demand could have been 21,518 MW, and the additional demand being bid in each hour, at higher bid prices, could have resulted in roughly $\$ 6.7$ million in additional costs to the system (i.e., all customers). This estimate is based on the difference in what the market clearing price could have been in each of the 13 hours absent the $115 \mathrm{MW}$ of demand savings, and the actual market clearing price in each of those hours, times the demand in the spot market. ${ }^{14}$ DOER estimates that absent the demand savings from the energy efficiency programs, the average market clearing price over the 13 hour period could have been $\$ 554$ per MW (the highest hourly price being $\$ 999$ per MW), or $40 \%$ higher than the average market clearing price absent the impact of the $115 \mathrm{MW}$ demand savings." (MA DOER, 2000)

\footnotetext{
${ }^{13}$ For simplicity, the DOER analysis assumes that the distribution companies' combined coincident peak demand reductions of $115 \mathrm{MW}$ occurred in these hours on June $7^{\text {th }}, 1999$.

${ }^{14}$ Massachusetts DOER's 1999 analysis (including load data, bid schedules, and market clearing prices) is based upon data reported by ISO-NE. Note that the $\$ 6.7$ million in savings reflects savings to the spot market load (i.e., what was traded in the spot market in each hour), as opposed to total load (most of which is traded through bilateral contracts). The average spot market load over the 13-hour period was 3,159 MW. See Massachusetts DOER annual report for details.
} 
The figure below illustrates the impact of Massachusetts energy efficiency and DSM load reductions on market clearing prices during a 13-hour period on June 7,1999. In addition to the energy efficiency programs lowering the program participants' energy costs by $\$ 20$ million in 1999, DOER concluded the programs provided reliability benefits and power cost savings to all customers - and the value of the market price benefit on one high-cost day was over $\$ 6$ million.

\section{Impact of Massachusetts DSM on Spot Market Clearing Price June 7, 1999}

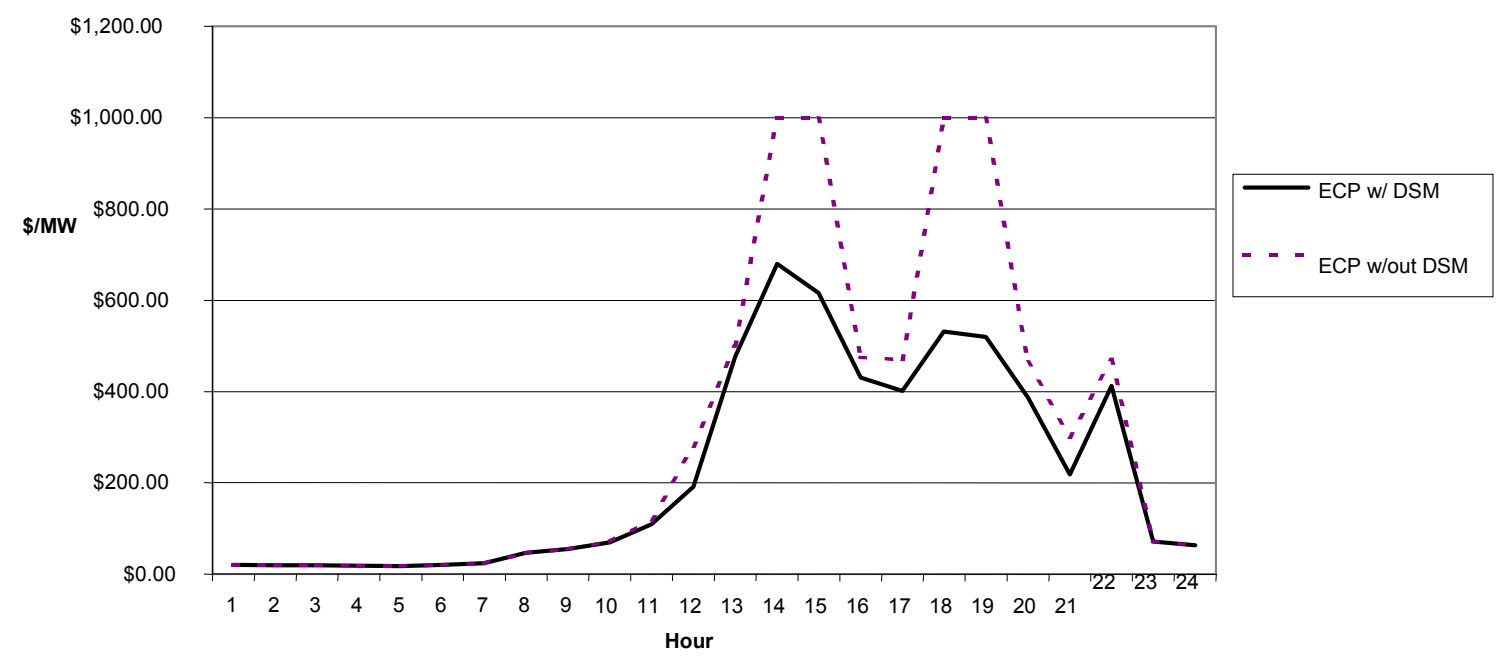

In Efficient Reliability, Cowart summarized similar impacts of energy efficiency on market clearing prices in California and the PJM region, but points out that these savings occur in many hours over the load shape and not just during peak hours:

"The savings resulting from energy efficiency are obviously very high at peak, but they are also surprisingly high when all other hours of the year are considered. Looking at the price curves in both California and the PJM region over every hour in recent years yields the conclusion that the benefits of energy efficiency investments to customers in the pool generally substantially exceed the private benefits of efficiency to those who install efficiency measures. For example, in the PJM market the value of load reduction was as high as $\$ 114$ per MWh and averaged $\$ 67.67$ per MWh (6.7 cents $\mathrm{kWh}$ ) across all hours. Enormous amounts of energy efficiency are available at far less than $\$ 67.67$ per MWh. In a similar study done in California for the period June 1998 through May 1999, before the continuous high PX prices of 2000-2001, the savings per average $\mathrm{kWh}$ reduction across all hours was 7.51 cents. With a great untapped reservoir of demand reduction available at less than 4 cents per $\mathrm{kWh}$, customers exposed to market 
prices will be paying a high and unnecessary price when efficiency programs are not pursued in their market regions." 15

When the margin between available generation and load is thin, and the ability of generators to charge high prices for supply-side resources is high, load reductions from energy efficiency and other demand-side resources moderate the market power of generators, and reduce their ability to raise market prices well above the marginal cost of production. ${ }^{16}$ The result is increased competitiveness in the market, with benefits provided to all consumers.

\section{F. Energy Efficiency as a Distributed Resource}

Energy efficiency resources are modular and dispersed throughout the grid, and therefore are available in countless locations. As such, energy efficiency is a highly reliable distributed resource in comparison with most generation resources. In addition, energy efficiency does not need transmission or distribution to move the resource to its point of use, therefore it avoids T\&D costs, reliability concerns, security risks, and environmental and local community impacts.

In Efficient Reliability, Cowart explained that 1,000 MW of energy efficiency is not the same as 1,000 MW of large-scale generation:

"For example, in early January, 2001, 30\% of California's generating capacity was unavailable because of heavy offshore waves, which threatened to block cooling intake pipes with kelp. On January 17-19, 11,000 MW of generation capacity was out of service for maintenance following heavy service in the previous summer. On those days the state was experiencing Stage III alerts, and 500,000 customers experienced rolling blackouts. Meanwhile, the installed base of efficiency resources was "on" and delivering significant benefits to the network."

\section{G. Targeted Energy Efficiency Efforts}

Energy efficiency can help improve reliability, defer or avoid transmission and distribution investments, and relieve constraints and load pockets.

In the Mad River Valley of Vermont, a combination of a load management agreement with a ski area and energy efficiency in the community avoided an expensive upgrade and maintained reliable service in a rapidly-growing resort community. The ski area's load management efforts, together with the energy efficiency savings, reduced the utility's peak power loads. Utility studies concluded that the appropriate distribution upgrade would have been a parallel $34.5 \mathrm{kv}$ line, at a cost of at least $\$ 5$ million.

\footnotetext{
${ }^{15}$ See Rich Ferguson, The Public Value of Load Reduction in the California Market -Preliminary Results, CEERT (July, 1999) (finding the public annual savings per MW of baseload reduction to be $\$ 650,000$, or three times the direct power cost savings to conserving customers), and William Marcus and Greg Ruszovan, "Cost Curve Analysis of the California Power Markets" Testimony in App. 99-03-014, CA PUC (September 2000).

${ }^{16}$ See Richard Cowart, Efficient Reliability, for a more complete discussion.
} 
Other past and current targeted energy efficiency projects include projects in California (the Delta project), Chicago, and New York.

In May 2002, the Connecticut Energy Conservation Management Board (ECMB) resolved:

"ECMB encourages the DPUC, FERC, ISO-NE, and the Connecticut Legislature to implement integrated resource planning for the electricity system, including integrated transmission and distribution planning, to ensure that cost-effective C\&LM and distributed resources are considered and analyzed as viable alternatives to supplyside transmission and distribution investments."

\section{H. Remaining Potential and Goals for Energy Efficiency}

What is the remaining potential of cost-effective energy efficiency, nationally and in New England?

In terms of the nation, a 1997 study prepared for US DOE by the five National Energy Laboratories found that cost-effective energy efficiency investments could displace $15 \%$ to $16 \%$ of the nation's total electrical consumption by the year 2010 (Interlaboratory Working Group, 1997). A 1999 study by the American Council for an Energy-Efficient Economy (ACEEE) estimates that adopting a comprehensive set of energy efficiency policies could lower national energy use by as much as 18\% in 2010 and $33 \%$ in 2020, and do so cost-effectively (Nadel and Geller, 2001). ACEEE also concluded, in a 2000 study, that energy efficiency programs targeted to reduce peak electricity demand could displace approximately 64,000 MW of generation capacity within a decade nationwide (Nadel et al, 2000).

In New England, in 2001 Massachusetts DOER conducted a study to examine the potential for additional energy efficiency achievements in Massachusetts (RLW \& SFMC, 2001). The study concluded that while Massachusetts had made significant gains in energy efficiency as the result of past programs, there remained significant potential for continued cost-effective investments in energy efficiency. This research estimated that residential programs could continue to achieve an average of $67 \mathrm{GWh}$ of savings each year for the period 20032007. For the commercial and industrial sectors, the research estimated that programs could achieve about 170 GWh in energy savings per year.

The New England Council, a meta-Chamber of Commerce for the region, issued a Report and Agenda for Action in August 2001 crediting government, business, and other leaders with policies that kept growth in energy consumption to 25 percent between 1980 and 1999 , even as the region's economy more than doubled. The report called for more of the same in the future. 
In Vermont, Governor Howard Dean's Energy Initiative, issued in December 2001, calls on citizens, businesses, utilities, and government to work together to meet all growth in demand for power over the next decade through a combination of efficiency, renewable energy generation, and increased use of combined heat and power applications. ${ }^{17}$

In Texas, ERCOT is addressing reliability and transmission needs partly through demand-side resources, and the PUC set a standard to achieve efficiency savings equivalent to $10 \%$ of load growth.

In January 2002, the Northwest Power Planning Council (NWPPC) encouraged the Pacific Northwest region electric utilities and large industries to lower the regional demand for electricity by building a "conservation power plant" over the next three years. The NWPPC set this three-year goal in response to an analysis by the Council's power planning staff that found that 300 average megawatts of cost-effective energy efficiency could be installed in the Northwest over the next few years.

According to the analysis by NWPPC staff, the Pacific Northwest region could acquire "approximately 100-110 megawatts of new conservation per year for the next three years for less than the cost of power from a new combustion turbine - about 3 cents per kilowatt-hour for the conservation." The Council's proposed 300-megawatt "conservation power plant" is a voluntary target only, not a requirement, and it is based on staff's analysis of what is cost-effective in the region. (NWPPC; October 18, 2001, and January 16,2002 )

Should New England policy makers consider setting regional energy efficiency goals, and should a regional energy efficiency assessment (or a series of coordinated state assessments) be conducted to assist in setting such goals?

\footnotetext{
${ }^{17}$ The Vermont Department of Public Service is completing a study of energy efficiency potential in Vermont that should be completed in late May 2002.
} 


\section{Energy Efficiency in a Market Framework}

If energy efficiency is so beneficial to customers and society, and if it can be achieved at costs less than supply resources, why isn't more energy efficiency being implemented in private competitive markets in New England?

The answers to this question lie in (1) market barriers to private investment in energy efficiency, and (2) market and institutional barriers to energy efficiency being used as a system resource. This section summarizes market barriers to private investment, market and institutional barriers to achieving the public and system benefits of energy efficiency, and the market orientation of energy efficiency programs.

\section{A. Market Barriers}

Cost-effective energy efficiency resources in New England are often untapped in the private competitive market due to significant market barriers faced by customers and other market participants (e.g., retailers, distributors, manufacturers, builders, contractors, and property managers). These market barriers include information or search costs, hassle and transaction costs, performance uncertainties, market response uncertainties, asymmetric information and opportunism, product or service unavailability, infrastructure limitations, uneven product quality, limited access to financing, bounded rationality (behavior during the decision making process that appears to be inconsistent with stated goals), organizational practices or customs, split incentives, inseparability of product features, irreversibility, the failure of prices to reflect the time-differentiated nature of demand and energy use, and the failure of market electricity prices to reflect the full cost of energy to society including environmental and social externalities.

Some large customers see electricity as a commodity, and they are willing to shop for better prices or for other alternatives. But most small customers see energy as a service, and generally they do not shop for or consider other choices. Also, energy efficiency is more of a product or service attribute, rather than a distinct product or service with its own market. Even when customers are interested in exploring alternatives, the market barriers listed above limit their ability to consider and adopt energy efficiency products and services. These market barriers also limit the perceived viability of and market size for energy efficiency products and services in the minds of manufacturers and suppliers.

Even in competitive retail electric market systems proposed by restructuring advocates, most of these market barriers to energy efficiency will remain. The failure of prices to reflect the time-differentiated nature of demand and energy use appears to be the only market barrier in the above list that will be substantially reduced. Therefore, most of the cost-effective energy efficiency resources that could provide net benefits to New England and its customers will not be acquired in the competitive market, absent intervention. The end result of a competitive-market-only approach would be an electricity market with higher societal costs for electric energy services, higher customer bills, less efficiency, fewer jobs, and more environmental damage. 


\section{B. Institutional Barriers}

In addition to the market barriers summarized above, there are several institutional barriers to energy efficiency being used as a system resource in the developing power markets:

- In general, wholesale energy markets are just beginning to build in a demand-side, with almost all focus to date on demand response on short-term (day ahead) commodity markets.

- Currently, market development has a short-term commodity and price focus versus a longer-term resources and value focus.

- Energy efficiency resources are not dispatchable in the manner that generation resources are.

- The public nature of some energy efficiency benefits versus the private nature of the customer investments.

- The timing and nature of energy efficiency investments (payment upfront) versus the benefit stream (benefits accrue over time).

- De-integration of the electricity system into component parts.

- No integrated least cost planning to assess alternatives to supply options.

- No institutional forum or filing process for policy-makers to react to (unlike generation plant or transmission line siting).

Kushler and others have concluded that special public policy emphasis is necessary to make energy efficiency programs happen in the developing market structure, even relative to other demand response efforts such as load management, in order to achieve the public and consumer benefits of energy efficiency (Kushler et al, 2002).

\section{Market Orientation of Energy Efficiency Programs}

Publicly-funded energy efficiency programs can change or transform markets so that market barriers are reduced, and the level of energy efficiency adopted in the competitive market is increased. Most energy efficiency programs are market-oriented, in that the programs leverage and focus on naturally-occurring market opportunities, such as increasing energy efficiency when buying or building a new home, designing and building a new office building or facility, purchasing a new appliance, replacing old or failed equipment, modifying an industrial process, buying or replacing a heating or cooling system, or remodeling a home or business. The programs work with the market by focusing on market opportunities, working with market actors, reducing market barriers, and increasing opportunities for and adoption of energy efficiency.

The actual provision of energy efficiency services supported with system benefits or other funds can be competitive, and generally is competitive in the New England states. Contractors provide many program services, and, in general, these contractors are selected using competitive solicitations. This competitive outsourcing approach helps to develop an infrastructure in the private market. 
Energy efficiency programs in the past have been instrumental in transforming some markets, increasing the market adoption of energy efficient products and services, and making energy efficiency more of a standard practice in the competitive market. For example, in commercial lighting, T-8 lamps and electronic ballasts became standard practice in owner-occupied office buildings and other facilities after significant efforts by utility energy efficiency programs in many states, including financial incentives, information and technical assistance, contractor training, and testing and program standards to ensure quality equipment and installation. On the residential side, there have been significant increases in the energy efficiency of new air conditioners, refrigerators, clothes washers, and other appliances over the last 20 years, driven in part by publiclyfunded energy efficiency programs. These efficiency improvements were then extended to all new products through state or federal appliance efficiency standards. 


\section{Energy Efficiency Options}

This section describes funding, program focus, and coordination options for increasing energy efficiency in New England. First, the primary funding and program focus options are presented. Second, two regional approaches - a regional pool benefits fund and enhanced regional coordination - are summarized. Technology and complementary options (such as financing support) are included near the end of the section, followed by a table summarizing all of the primary options, and a list of program designs and targeted end uses for energy efficiency peak load demand response.

\section{A. Primary Funding and Program Focus Options}

There are five primary funding and program focus options for energy efficiency support:

1. State system benefits funds collected through wires charges to support broad-based energy efficiency programs and activities. ${ }^{18}$

2. Regional pool benefits programs funded through transmission tariffs or uplift charges, for programs with cost-effective regional reliability or pool benefits.

3. Building codes and appliance and equipment standards to reduce inefficient load and to lock in efficiency gains in the marketplace.

4. Targeted least-cost distribution investments by distribution companies to defer or reduce future wires investments, or to relieve distribution constraints, financed with utility funds and recovered through future revenues, or recovered through pool reimbursement for load reductions.

5. Targeted least-cost transmission investments by transmission companies or the regional pool to defer or reduce future wires investments, or to relieve transmission constrained areas, financed with transmission company funds and recovered through future revenues, or financed through the regional pool, with wires investments subject to bidding and open season mechanisms.

The figure below summarizes the primary funding and program focus options for support of energy efficiency. The options are organized by the primary program focus (row headings), including broad based, peak load targeted, and geographically targeted, and by the geographical spectrum of regional to local. Note that (1) state system benefits funds and (2) codes and standards are two distinct options that are similar in their broad-based focus and in geographical spectrum, therefore they occupy the same rectangle in the figure.

\footnotetext{
${ }^{18}$ Within the state system benefits fund programs, the relative focus on achieving peak demand savings $(\mathrm{kW})$ could be increased to increase the demand response impact of the programs.
} 
Energy Efficiency Options for the New England Demand Response Initiative (NEDRI) - Framing Paper \#4

\section{Primary Funding and Program Focus Options for Energy Efficiency Support}

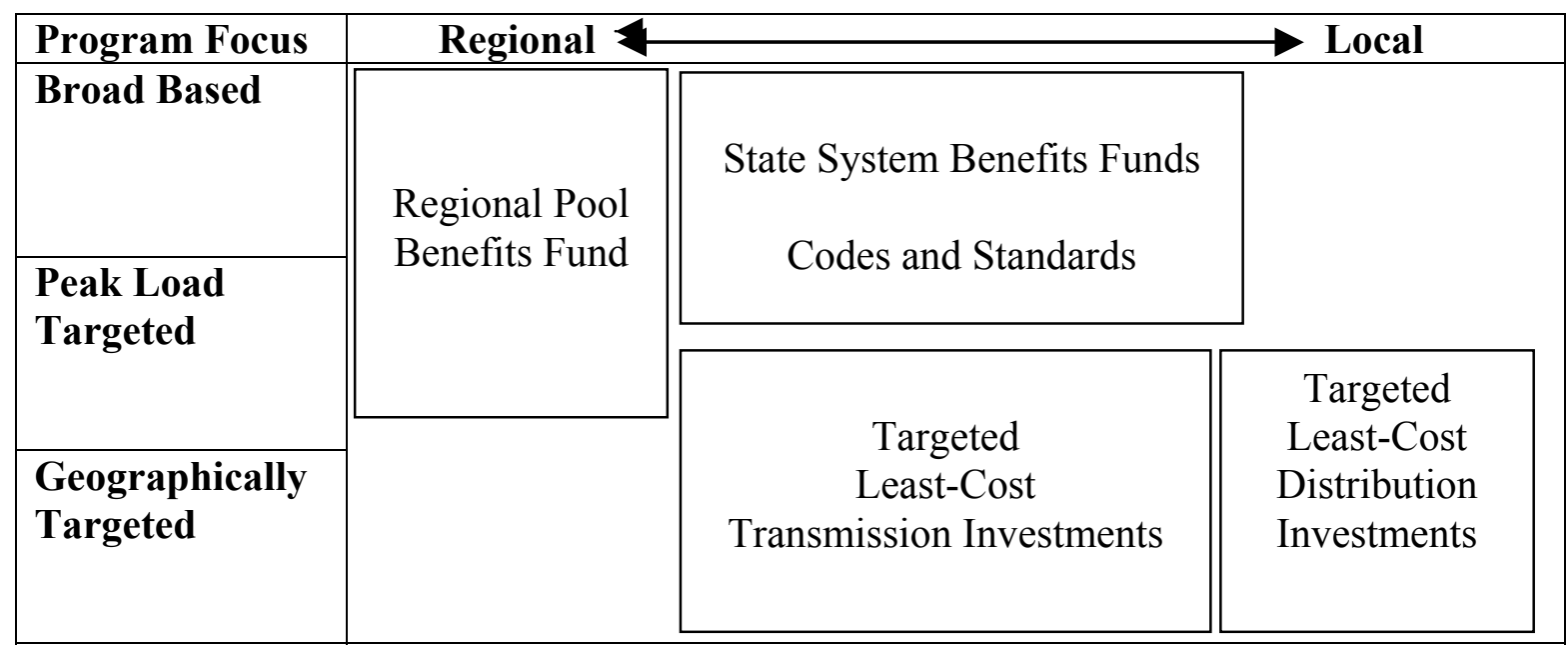

\section{B. Regional Pool Benefits Fund}

In the past, energy efficiency programs were funded and administered at either the utility franchise or the state level. The boundaries of the funding and the programs were the utility service territory or the state lines. Today, power markets are regional, with regional pools, transmission grids, system operations, reliability rules, and socialized funding and investment mechanisms. In addition, markets for many energy-related products and services are regional or national. And the benefits of energy efficiency flow to consumers across the power pool - they do not stop at state lines or utility service boundaries. Therefore, policy makers could consider broad-based regional pool funding for energy efficiency programs.

Regional power managers are responsible for securing regional resources - generation, ancillary services, reserves, and transmission - on a regional basis. Regional pool benefits funding could be considered, by regional power managers or other regional organizations, whenever energy efficiency programs provide cost-effective benefits to regional power markets, regional resources, regional reliability, regional transmission systems, and/or other regional needs. Implementing a least-cost integrated resource planning process could assist in identifying cost-effective energy efficiency and other alternative resources. Also, as documented earlier in this paper, energy efficiency can provide benefits to all consumers in a regional pool by reducing the market price of power.

Regional pool benefits funding could be administered at the regional level, such as through a regional energy efficiency or demand-side resources coordinating council. Or the regional pool funding could be allocated to each state and administered jointly with the state system benefits funds programs (see issues discussion in Section V).

\section{Enhanced Regional Coordination}


Enhanced regional coordination could increase the effectiveness and cost-efficiency of energy efficiency efforts in New England. With a regional grid, a regional power market, and a regional pool, it may make sense in some cases to plan, analyze, and implement energy efficiency and demand-side resources on a regional basis rather than by state. Three aspects of enhanced regional coordination should be considered - regional programs, regional coordinating organizations, and regional planning, resource assessment, and evaluation.

Regional programs may be more effective for some opportunities because of the nature of the technology, the avenue of commerce, the market opportunity, or the program strategy. Two examples of high priorities for regional efforts are market transformation programs that focus on regional or national markets, and appliance and equipment standards.

There is regional program coordination across New England states for several programs already: NEEP facilitates many regional programs that are supported by SBC funds and jointly-administered by the program administrators in each state; CEE provides technical and program assistance on regional and national opportunities; the SBC program administrators are participants in several national and regional consortia; and regional implementation contractors assist in coordinating regional programs across the states.

For a given energy efficiency program or effort, one question is: regional implementation or regional coordination? Policy makers should consider the pros and cons of regional programs administered and implemented regionally versus regional coordination of state programs, for SBC-funded programs as well as appliance and equipment standards.

New England policy makers and other stakeholders could evaluate the merits of a regional coordinating council for energy efficiency programs, including SBC-funded programs and appliance and equipment standards. ${ }^{19}$ The coordinating council could assess regional opportunities, prepare regional plans for energy efficiency and other demand-side resources, coordinate regional implementation, and conduct regional evaluations. In the Pacific Northwest, the Northwest Power Planning Council and the Northwest Energy Efficiency Alliance (a non-profit organization with a board comprised of utility, government, and stakeholder representatives) plan and implement regional programs.

In the absence of a regional coordinating council, some planning, resource assessment, and evaluation activities could be conducted regionally, through joint efforts of state administrators.

\footnotetext{
${ }^{19}$ See discussion by Jonathan Raab and Jane Peters, in A Comparative Study of the Northwest Energy Efficiency Alliance and the Northeast Energy Efficiency Partnership, prepared for NARUC in 1998.
} 


\section{Other Complementary Approaches}

There are several complementary approaches, such as financing support, shared savings programs, and Pay As You Save (PAYS) programs, which can increase adoption of energy efficiency in New England. Under the PAYS approach, a customer's investment in approved energy-efficient equipment is financed by a utility, an energy service provider, or a system benefits fund. The investment is repaid through a charge on the customer's utility bill, which gives the customer an easy means of repayment, and gives the financing entity a low-risk repayment schedule. If widely implemented, financing programs like PAYS could stimulate adoption of energy efficiency measures, particularly in the residential sector or for any customer for whom financing is the key or an important market barrier.

These approaches are complementary in that they could be implemented in any or all of the primary funding and program focus options described above, where appropriate and effective.

\section{E. Technology Options for Joint Delivery of Efficiency and Load Management}

Some technology options, such as smart chips in energy efficient appliances, improve energy efficiency while at the same time increasing the enabling infrastructure for load management demand response. Smart thermostats linked to paging technology also have the potential to increase demand response, especially for residential customers who are currently under-addressed by most load management demand response programs, given their small individual loads and the transaction costs of aggregating and managing their loads. These options are being explored in pilots in New England and elsewhere.

\section{F. Options and Characteristics of Options for Energy Efficiency}

Below is a summary table that compares and contrasts the options for increasing energy efficiency in New England and the main characteristics of the options. The last column of the table highlights actions needed to develop, enable, or more effectively implement each option. 


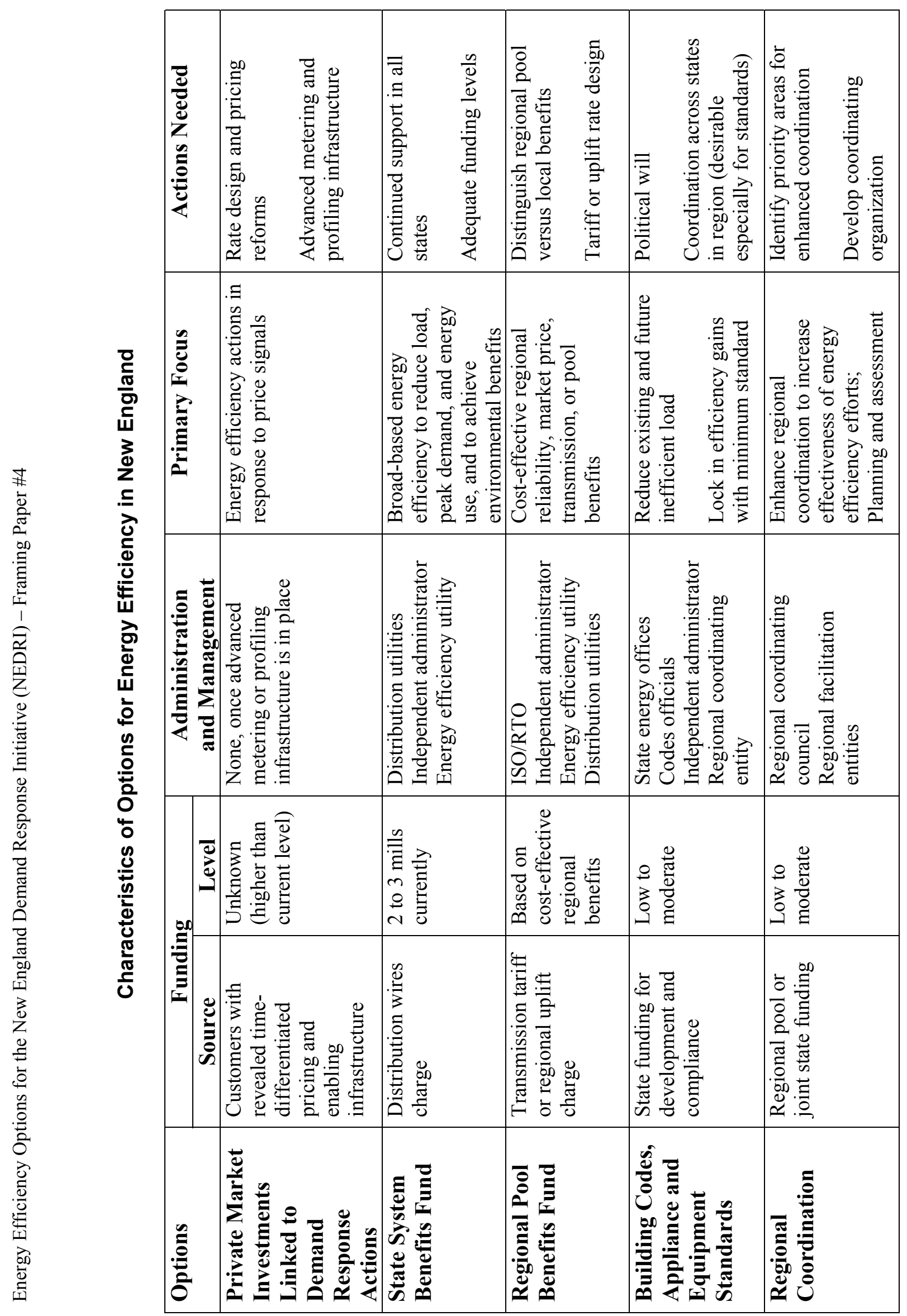




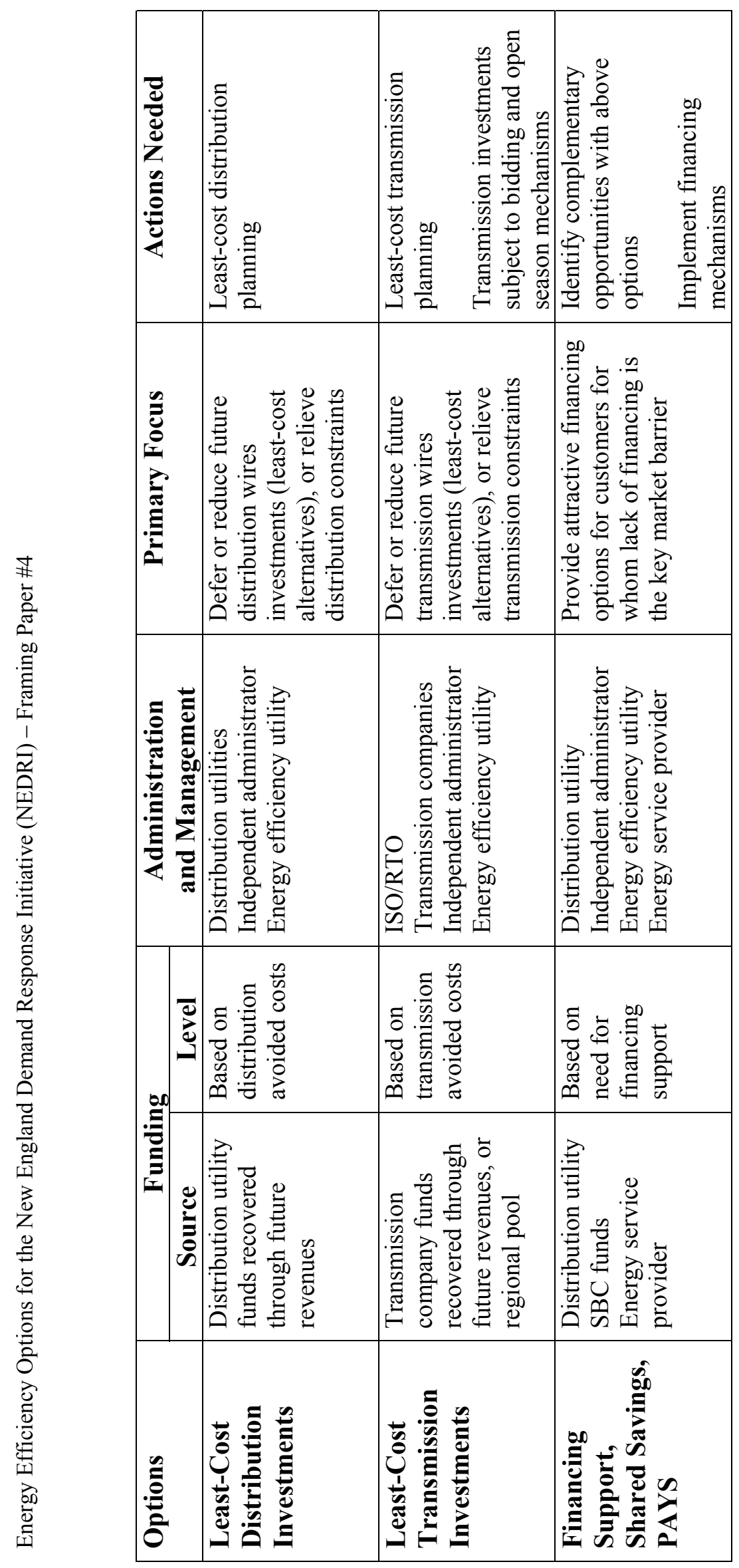




\section{G. Energy Efficiency Program Designs for Peak Load Demand Response}

Some energy efficiency programs and measures reduce peak demand more than others. Within the state system benefits fund programs, the relative focus on achieving peak demand savings $(\mathrm{kW})$ could be increased to increase the demand response impacts of the programs.

Below is a list of some key end uses that could be targeted and program designs that could be used to reduce peak demand:

- Commercial and industrial HVAC equipment and systems,

- Commercial building retrocommissioning, operation, and maintenance,

- Commercial and industrial lighting retrofit and lighting design,

- Custom and industrial process programs,

- Motors and drives,

- Residential cooling systems (new, replacement, and tune-up and repair, with performance testing and proper sizing),

- Residential refrigerators,

- New construction programs (i.e., add only efficient load), and

- Building codes and appliance and equipment standards focused on energy efficiency measures that reduce peak demand.

One potential opportunity for increasing peak demand savings and therefore demand response from current SBC-funded energy efficiency programs is to consider redeploying and reorienting the existing broad-based programs, which are focused on multiple objectives, and increase the emphasis on achieving peak demand savings. In general, most of the existing SBC-funded programs are not targeted specifically or primarily to achieve summer peak demand savings. Increasing the focus on the objective of summer peak savings would likely increase the annual summer peak load reductions going forward. However, with fixed funding levels for SBC portfolios in most states, any increase in emphasis on one of the multiple objectives would tend to decrease emphasis on another objective. Therefore, consideration of this possibility should be done in a balancing process, with stakeholder participation, which considers all of the goals and objectives of SBC-funded energy efficiency programs. 


\section{Policy, Program and Market Issues}

Energy efficiency policy, program, and market issues are listed below as topics for NEDRI stakeholder consideration and discussion.

\section{Market mechanisms to increase energy efficiency.}

Working within the framework of the electricity market structure that is being designed and developed in New England, what market mechanisms, including regulatory or institutional actions and rules that support markets, could be implemented to better realize the potential and better reflect the value of energy efficiency? How, when, and to what degree will market mechanisms encourage energy-efficient load and discourage inefficient load?

Are there market mechanisms and institutional actions that would increase the private adoption of energy efficiency, thereby encouraging efficient load and discouraging inefficient load? Other NEDRI papers have identified improvements in pricing and rate design that would better communicate the time-differentiated nature and price/cost of demand to customers, thereby increasing demand response. To what degree will potential changes in pricing and rate design increase investments in energy efficiency, as well as short-term demand response? Could the region design efficiency measures to piggy-back on the consumer awareness generated by more accurate pricing? How could the region design load interruption programs so that they do not undermine cost-effective efficiency initiatives (e.g., how rapidly should the consumer baseline ratchet downward as efficiency measures are deployed?)

In addition to the pricing and rate design reforms discussed in the previous NEDRI framing papers and elsewhere, are there market changes that would address the longerterm, upfront investment, disaggregated, and systematic load reduction aspects of energy efficiency?

When would any such market mechanisms be fully implemented? What should be done in the meantime?

\section{Private market activity and remaining market barriers.}

What level of cost-effective energy efficiency is likely to be achieved in the private market through market mechanisms? Which market barriers will remain and how can they be addressed?

Improvements in markets and supporting institutional mechanisms, including improvements in pricing and rate design, should result in increases in private adoption of energy efficiency. However, fundamental market barriers will remain (see discussion in Section III). The end result will be continued substantial under-investment in energy efficiency and over-investment in supply-side systems to serve inefficient load. 
The region will also need to track the pace at which "lost opportunities" are arising on the New England grid during the current transition to a more competitive market regime. Until improvements in demand side markets are fully implemented, and market barriers to efficiency reduced significantly, existing market barriers with substantial negative impacts still need to be addressed. Each time a customer selects an inefficient product or service compared to an energy efficient one, there is a lost opportunity, and inefficient load is added to the grid. The inefficient load will remain on the grid for years, until it is retrofitted or replaced.

\section{Options for funding and support of energy efficiency.}

\section{How can the states and the New England region best capture the various public benefits of energy efficiency with public or pool funding and programs?}

Since for the foreseeable future the public and system value of energy efficiency exceeds the level of private investment, there are several options for public and system support of energy efficiency, including:

- State system benefits funds collected through wires charges to support broad-based energy efficiency programs and activities;

- Regional pool benefits programs funded through transmission tariffs or uplift charges, for programs with cost-effective regional reliability or pool benefits;

- Building codes and appliance and equipment standards to reduce inefficient load and to lock in efficiency gains in the marketplace;

- Targeted least-cost distribution investments by distribution companies to defer or reduce future wires investments, or to relieve distribution constraints, financed with utility funds and recovered through future revenues, or recovered through pool reimbursement for load reductions;

- Targeted least-cost transmission investments by transmission companies or the regional pool to defer or reduce future wires investments, or to relieve transmission constrained areas, financed with transmission company funds and recovered through future revenues, or financed through the regional pool, with wires investments subject to bidding and open season mechanisms;

- Enhanced regional coordination to improve the effectiveness and efficiency of energy efficiency efforts in New England, possibly through a regional energy efficiency coordinating council;

- Other complementary approaches such as financing support, shared savings programs, and Pay As You Save (PAYS) programs; and

- Fiscal policies such as tax incentives.

Currently, each New England state is supporting and funding energy efficiency at some level. The question is: should the states, regional entities, and/or the utilities be doing more, after considering the above list of options? 


\section{Who should pay for the various public benefits of energy efficiency? ${ }^{20}$}

\section{One fundamental question is who should pay to support energy efficiency investments (in addition to participating customers): the broad-based state system benefits fund, the regional pool through transmission tariffs or an uplift charge, transmission companies and distribution utilities to defer or avoid $\mathbf{T} \& \mathbf{D}$ investments, state governments, taxpayers at large, or some combination?}

Should broad-based state system benefits funds be expected to address and pay for meeting regional pool (e.g., reliability) and local area (e.g., constrained area) needs? Are the existing state system benefits programs expected to fund energy efficiency and demand response programs (emergency reliability and price-responsive load)? At funding levels of 2 to 3 mills in New England, the state system benefits funds are hard pressed to address the energy efficiency lost opportunities in the marketplace, much less other needs. Is it politically feasible for state system benefits funding levels to be increased to meet additional needs and requests for funding?

One way to state the above question in reverse is to ask: will the ISO/pool provide funding for regional and/or targeted energy efficiency efforts that provide regional benefits in a regionally cost-effective manner, as well as for emergency and priceresponsive load programs?

There are several aspects of this issue that policy makers should consider:

- For any state or regional pool investment, where should the investment capital come from, and how should the investment capital be recovered or repaid?

- If the pool is planning to socialize the costs of supply investments (transmission, reliability, ancillary services, reserves, environmental damage, etc.) across the entire regional pool, should the costs of energy efficiency (and other demand-side resources) that provide regional resources also be socialized across the pool?

- Should energy efficiency and other demand-side resource funding mechanisms parallel the funding mechanisms used to pay for the supply and reliability investments they reduce, defer, or replace?

- In the market being designed (SMD), are these funding mechanisms expected to be socialized across the entire pool, or localized?

- Under locational-based marginal pricing, are there funding mechanisms that could be used to help relieve the local constraints and load pockets through accelerated adoption of targeted energy efficiency, demand-side resources, and other distributed resources?

Policy makers should consider these issues in a pro and con analysis when deciding who should pay for which investments, and what payment and recovery mechanisms should be used.

\footnotetext{
${ }^{20}$ In this discussion of policy issues, the potential funding sources and related issues (\# 4 and \# 5) are discussed separately from which and how many organizations should administer the programs (\# 6).
} 
5. Valuing energy efficiency benefits in an integrated manner, within a deintegrated market system.

If multiple funding sources are used, how can the integrated benefits of energy efficiency be maintained, represented, assessed, and fully valued, rather than being de-integrated and marginalized?

Energy efficiency has multiple benefits and can meet multiple objectives - energy efficiency will lower environmental impacts and distribution and transmission costs, as well as peak demand and energy costs. In the past, under an integrated system planning framework for integrated utilities, the multiple benefits of energy efficiency for meeting various system needs could be integrated and represented in one analysis. But with the current de-integrated market system, the specific benefits of energy efficiency are also de-integrated in terms of the specific market or system segment to which the benefits accrue. Thus, an energy efficiency investment that is cost-effective for the system would not appear as cost-effective if its total costs were compared to just one of its disaggregated benefits, such as avoided generation costs, or avoided marginal distribution costs.

Currently most analyses of SBC fund programs are conducted in an integrated manner at the state level (though they generally do not fully incorporate some of the pool and market benefits that energy efficiency has provided in recent years, such as increased reliability and diversity, and reduced market prices). How should regional analyses be conducted to represent, assess, and value the fully integrated nature of energy efficiency benefits? Is regional integrated or demand-side resource analysis possible? Can we design an analytic process to evaluate the full merits of efficiency investments without the necessity of a complete resource analysis for energy supply?

The framework for evaluating demand response programs is developing further and sharpening in approach, based on work in NY and elsewhere. ${ }^{21}$ Improved valuation of energy efficiency should be done in parallel with work on demand response valuation.

\section{Administration of energy efficiency programs.}

While funding from multiple sources may have merit, what are the pros and cons of having multiple administrators for energy efficiency efforts, with defined roles and responsibilities focused on distinct needs? Or, on the other end of the spectrum, should state system benefits funds be enhanced and broadened explicitly, with increased funding from other sources, and with state $\mathrm{SBC}$ administrators focusing on regional pool, transmission and local distribution needs as well as broad-based energy efficiency programs?

How do the region and states develop a system of administration and coordination that shares energy efficiency funding from multiple sources (and that could conduct planning

${ }^{21}$ See Neenan Associates, 2001. Valuing Investments in Developing Customer Price Responsiveness. Working Paper, December 2001. 
and/or resource assessment on a regional basis), but that doesn't create inefficiencies, conflicts, and turf battles among multiple administrators? At least three levels of administration are possible: (a) programs offered by distribution companies that focus solely on local needs and distribution values; (b) state SBC administration; and (c) regional administration of pool-level programs for reliability, transmission needs, and regional market benefits. Should all three be pursued independently, or on a coordinated basis, or should administration be consolidated? One possibility is to expand both the funding and responsibility of individual state programs. Alternatively, the region could develop an energy efficiency responsibility at the regional level, with an appropriate governing mechanism, to work in conjunction with the various state programs.

Are there any risks of undoing some of the positive aspects of current state system benefits planning and support for energy efficiency by relying partially on other funding sources or administrators, including the regional pool, transmission companies, and distribution utilities? Are some administrators more aligned, supportive of, and experienced with energy efficiency than others?

Does current state system benefits fund planning already value regional benefits to some degree? Does state SBC planning value and incorporate distribution and transmission benefits (and if so, on an average or marginal basis)? With multiple administrators, is there a risk that values such as avoided marginal distribution costs could be de-integrated or removed from the state SBC analyses?

\section{State system benefits fund support and related issues.}

\section{How can the states and region best support broad-based state system benefits funds and programs? Should SBC programs be reoriented to increase the focus on achieving peak demand savings?}

There are a number of questions here: (a) How can the states work together to ensure adequate system benefits funding for energy efficiency in all states in the region? To ensure equitable regional investment and continued progress on environmental, price, and reliability goals, should the region consider adopting a minimum funding or efficiency performance level as a pool requirement? (b) Who should administer and deliver state system benefits programs? (c) Will wires company rate designs be reformed to remove or at least reduce the substantial disincentive that wires companies experience, under current price cap rate designs based on throughput, when load is reduced? Will revenue caps, rather than price caps or higher fixed charges, be implemented?

Should policy makers and stakeholders consider redeploying and reorienting the existing broad-based SBC-funded energy efficiency programs, which are currently focused on multiple objectives, and increase the emphasis on achieving peak demand savings? Increasing the focus on the objective of peak demand savings may decrease emphasis on other important objectives. Therefore, could this be considered in a balancing process, with stakeholder participation, which considers all of the goals and objectives of SBCfunded energy efficiency programs? 


\section{Regional pool benefits funds.}

If created, how could the region best support and administer regional pool benefits programs funded through transmission tariffs or uplift charges?

If region-wide efficiency programs were created, what institutional and regulatory reforms would be needed? What should be the primary focus of such funding (e.g., regional reliability benefits, market price benefits, transmission alternatives, other pool benefits)? Who should administer and deliver the regional programs on behalf of the pool? Is an administrator separate from the system benefits fund administrators in each state warranted? What program designs would be most effective for regional pool benefits programs?

\section{Building codes and appliance and equipment standards.}

How should building codes and equipment standards be employed in the region to reduce inefficient load currently on the system, and to decrease the amount of inefficient load being added to the grid?

Given the demonstrated value of codes and standards to the states and the New England region, and the large potential future benefits, how should codes and standards be supported and implemented? How should regional coordination be increased to increase the effectiveness of the codes and standards in the markets across the region? Should New England support state appliance and efficiency standards, in addition to federal standards, similar to California? What state and regional policies are needed to increase support for and the effectiveness of codes and standards?

\section{Enhanced regional coordination.}

How could regional coordination be enhanced to improve the effectiveness and efficiency of energy efficiency efforts in New England? Are there energy efficiency efforts and programs (either existing or new programs) that could be more effective in providing region-wide benefits to the entire region if they were coordinated or implemented regionally?

Enhanced regional coordination could increase the effectiveness and cost-efficiency of energy efficiency efforts in New England. With a regional grid, a regional power market, and a regional pool, does it make sense to plan, analyze, and implement the majority of energy efficiency and demand-side resources by state? Or should more planning, analysis, and implementation be done regionally? What are the pros and cons of enhanced regional coordination? Three aspects of regional coordination could be considered - regional programs, regional coordinating organizations, and regional planning, assessment, and evaluation.

Regional programs may be more effective for some opportunities because of the nature of the technology, the avenue of commerce, the market opportunity, or the program strategy. 
Two examples of high priorities for regional efforts are market transformation programs that focus on regional or national markets, and appliance and equipment standards.

For a given regional energy efficiency program or effort, one question is: what are the pros and cons of regional implementation versus regional coordination? One option is regional programs administered and implemented regionally. Another option is regional coordination of state programs, including system benefit fund programs as well as appliance and equipment standards.

In terms of regional coordinating organizations, should New England consider developing a regional coordinating council to enhance regional coordination of energy efficiency programs, similar to the Northwest Power Planning Council and the Northwest Energy Efficiency Alliance in the Pacific Northwest? What is the role of existing organizations, such as NEEP and CEE, in coordinating and facilitating regional efforts? What role do regional implementation contractors play in regional coordination?

In the absence of a regional coordinating council, some planning, resource assessment, and evaluation activities could be conducted regionally, through joint efforts of state administrators.

\section{Energy efficiency goals and assessment of remaining future potential.}

Should the region set energy efficiency and other demand-side resource goals? If so, how, and on what basis?

Should a regional resource assessment, or coordinated assessments in each state, be conducted to document remaining potential for energy efficiency? Would comparative analysis of recent performance across the states be valuable in goal setting and resource assessment?

\section{Targeted least-cost alternatives to distribution wires investments.}

What institutional and regulatory reforms are needed to encourage distribution utilities to conduct least-cost planning and to invest in targeted cost-effective energy efficiency resources to reduce load, as an alternative to focusing solely on distribution wire investments to serve existing and future inefficient load?

When planning for future wires investments, are there opportunities to assess alternative investments, and, where cost-effective, to fund geographically-targeted energy efficiency load reduction and other demand-side and distributed resources to defer or reduce wires investments? Will distribution utilities undertake such actions on their own? Or are the disincentives and institutional barriers too large to overcome without regulatory reform?

In addition to planning approaches, are there bidding and open season mechanisms that could be used to encourage competition between planned wires investments and energy efficiency (alone, or together with other demand-side and distributed resources)? 
Could transmission companies undertake similar least-cost planning and alternate investment activities to defer or reduce transmission wires investments? (See discussion below regarding regional approaches to constraints, congestion, and transmission wires investments.)

What is an effective approach for addressing the asymmetry in repayment streams for wires investments versus energy efficiency investments?

\section{Targeted efforts to relieve congestion and constraints, including least-cost} alternatives to transmission wires investments.

What institutional and regulatory reforms are needed to relieve congestion, or to defer or reduce transmission wires investments, through a combination of approaches, including targeted energy efficiency to reduce load, pricing and metering options implemented locally to encourage price response, demand response programs or contracts, and other distributed resources? ${ }^{22}$

Congestion is a signal of an imbalance between the supply infrastructure and the demand. Choices are available on both sides - to increase supply infrastructure, or to reduce load. What institutional or regulatory reforms are needed to increase consideration of demandside load reduction strategies and distributed resources to relieve constraints, or to defer or reduce transmission wires investments?

\section{Bidding energy efficiency load reductions into the pool.}

With or without regional pool-funded energy efficiency programs, could an entity (such as a statewide system benefits fund or buyers coop) bid into the pool to provide resources (reductions in load) and receive payment for the value of the energy efficiency resources? Could this approach be used both for regional needs and local area needs (constrained areas)?

For example, could SBC energy efficiency program energy savings, peak load reductions, and load shape impacts be removed from the base forecast, and then be purchased by the pool as longer-term resources for the regional grid, in the form of a must-run resource?

\section{Balancing influences on market development to more fully reflect the consumer} and public value of energy efficiency.

Could influence over market development in New England, and the institutional actions and rules that support the markets, be better balanced to more fully reflect the consumer and public goods value of energy efficiency and other demand-side resources?

How do regulators and industry institutions balance and deal with conflicts between what may be good for generators and transmission owners, what may be good for customers in the form of lower market prices and lower energy bills, and what may be good for society

${ }^{22}$ This topic is addressed more fully in a parallel NEDRI memo from Richard Cowart. 
in the form of public benefits of energy efficiency? Generation and transmission owners have historically dominated regional decision-making, but they were also subject to close state regulation and operated on principles of least-cost planning. In the current environment, that guidance is much weaker. Can the necessary balance be re-created through a combination of market mechanisms and policy initiatives?

Finally, when considering the long list of issues above, and the various options before the NEDRI stakeholders, the table of energy efficiency options in Section IV.F may be a useful tool for summarizing the options and focusing discussion on key issues. One way to approach the options would be to start with the state system benefits funds, the option already in place in all of the New England states, and then consider each additional option, the issues related to it, and the actions needed to develop or more fully implement the option, in turn. 
Energy Efficiency Options for the New England Demand Response Initiative (NEDRI) - Framing Paper \#4

\section{Bibliography}

CEC. The Energy Efficiency Public Goods Charge Report: Proposal for a New Millenium. California Energy Commission. December 1999.

Cowart, Richard. Efficient Reliability: The Critical Role of Demand-Side Resources in Power Systems and Markets. National Association of Regulatory Utility Commissioners, Regulatory Assistance Project. June 2001.

Cowart, Richard. Distributed Resources and Electric System Reliability. Regulatory Assistance Project. September 2001.

ECMB. Report of the Energy Conservation Management Board, Year 2001 Programs and Operations. Annual report to the Connecticut legislature. January 2001.

Geller, H., T. Kubo, and S. Nadel. Overall Savings from Federal Appliance and Equipment Efficiency Standards. American Council for an Energy Efficient Economy (ACEEE). 2001.

Goldman, Charles A., Galen Barbose, and Joseph Eto. California Customer Load Reductions During the Electricity Crisis: Did They Help Keep the Lights On? Lawrence Berkeley National Laboratory. April 2002.

Goldman, Charles A., Michael Kintner-Meyer, and Grayson Heffner. Do "Enabling Technologies" Affect Customer Performance in Price-Responsive Load Programs? Lawrence Berkeley National Laboratory, ACEEE Summer Study Proceedings, August 2002 (forthcoming).

Kushler, Martin, Ed Vine, and Dan York. Energy Efficiency and Electric System Reliability: A Look at Reliability-Focused Energy Efficiency Programs Used to Help Address the Electricity Crisis of 2001. ACEEE, April 2002.

Interlaboratory Working Group. Scenarios of U.S. Carbon Reductions: Potential Impacts of Energy Technologies by 2010 and Beyond. September 1997.

Massachusetts DOER. Energy Efficiency Activities 1999: A Report by the Division of Energy Resources. Massachusetts Division of Energy Resources. Spring 2001.

Nadel, Steven and Howard Geller. Smart Energy Policies: Saving Money and Reducing Pollutant Emissions Through Greater Energy Efficiency. ACEEE, September 2001.

Nadel, Steven, Fred Gordon, and Chris Neme. Using Targeted Energy Efficiency Programs to Reduce Peak Electrical Demand and Address Electric System Reliability Problems. ACEEE, November 2000. 
Nadel, Steven. Utility Energy Efficiency Programs: A Brief Synopsis of Past and Present Efforts. ACEEE, August 2000

Raab, Jonathan and Jane Peters. A Comparative Study of the Northwest Energy Efficiency Alliance and the Northeast Energy Efficiency Partnership. NARUC. December 1998.

Raynolds, Ned and Andrew deLaski. Energy Efficiency Standards: A Low-Cost, HighLeverage Policy for Northeast States. Northeast Energy Efficiency Partnerships, Inc. (NEEP). May 2002

RLW and SFMC, RLW Analytics and Shel Feldman Management Consulting. The Remaining Electric Energy Efficiency Opportunities in Massachusetts, Final Report. Massachusetts Division of Energy Resources. 2001. 